\title{
Elevated endothelial Sox2 causes lumen disruption and cerebral arteriovenous malformations
}

\author{
Jiayi Yao, ${ }^{1}$ Xiuju Wu, ${ }^{1}$ Daoqin Zhang, ${ }^{1}$ Lumin Wang, ${ }^{1,2}$ Li Zhang, ${ }^{1}$ Eric X. Reynolds, ${ }^{1}$ Carlos Hernandez, ${ }^{1}$ \\ Kristina I. Boström, ${ }^{1,3}$ and Yucheng Yao \\ 'Division of Cardiology, David Geffen School of Medicine at UCLA, Los Angeles, California, USA. Department of Cell Biology and Genetics, School of Basic Medical Sciences, \\ Xi'an jiaotong University Health Science Center, Xi'an, China. ${ }^{3} T$ he Molecular Biology Institute at UCLA, Los Angeles, California, USA.
}

\begin{abstract}
Lumen integrity in vascularization requires fully differentiated endothelial cells (ECs). Here, we report that endothelialmesenchymal transitions (EndMTs) emerged in ECs of cerebral arteriovenous malformation (AVMs) and caused disruption of the lumen or lumen disorder. We show that excessive Sry-box 2 (Sox2) signaling was responsible for the EndMTs in cerebral AVMs. EC-specific suppression of Sox2 normalized endothelial differentiation and lumen formation and improved the cerebral AVMs. Epigenetic studies showed that induction of Sox2 altered the cerebral-endothelial transcriptional landscape and identified jumonji domain-containing protein 5 (JMJD5) as a direct target of Sox2. Sox2 interacted with JMJD5 to induce EndMTs in cerebral ECs. Furthermore, we utilized a high-throughput system to identify the $\beta$-adrenergic antagonist pronethalol as an inhibitor of Sox2 expression. Treatment with pronethalol stabilized endothelial differentiation and lumen formation, which limited the cerebral AVMs.
\end{abstract}

\section{Introduction}

Cerebral arteriovenous malformations (AVMs) are common human vascular abnormalities. Clinical observations reveal that the vascular network and lumen develop improperly in cerebral AVMs, resulting in ruptures and hemorrhagic strokes that lead to neurological defects (1). Evidence shows that endothelial cells (ECs) play a major role in cerebral AVMs (1-4), and several anomalies in ECs, including defects in proliferation $(5,6)$, polarization (7), differentiation (2), cell-cell interactions (8), and cell recruitment, have been documented in AVMs

Under normal circumstances, endothelial differentiation is maintained to support vascular homeostasis and mature ECs coordinate and communicate with surrounding cells through cellcell signaling $(2,3,10-14)$. Disruptions in the signaling set the stage for vascular abnormalities. For example, excess endothelial bone morphogenetic protein (BMP) signaling and Notch signaling are known to cause cerebrovascular malformations $(2,14-16)$, and it has been reported that unwanted cell signaling changes endothelial fate in different forms of vascular disease and that ECs gain plasticity and undergo alternative lineage differentiation $(14,17$, 18). However, it is unclear whether such unwanted cell signaling alters endothelial characteristics in cerebral AVMs and how the ECs become direct pathogenic factors in such malformations.

Different vessels are precisely defined by the lumen size and distributed in the tissues to support the circulation of blood. Lumen formation is tightly controlled by lumen-associated genes,

Authorship note: JY and XW contributed equally to this work.

Conflict of interest: The authors have declared that no conflict of interest exists.

Copyright: (5) 2019, American Society for Clinical Investigation.

Submitted: November 2, 2018; Accepted: April 23, 2019; Published: June 24, 2019

Reference information: / Clin Invest. 2019;129(8):3121-3133.

https://doi.org/10.1172/JCl125965. such as $\beta_{1}$ integrin, Par-3 family cell polarity regulator (Par3), and cytoskeletal regulator Ras interacting protein 1 (Rasip1) (19-21). These genes regulate interactions and polarization of ECs, and alterations in their expression cause lumen disruption (19-21). In AVMs, arterial-venous shunts directly connect the feeding arteries and collecting veins, bypassing the capillary networks. The lumens of the arterial-venous shunts are larger than normal capillaries and allow the blood flow to make shortcuts through the tissue, resulting in impaired delivery of oxygen and nutrients to the affected tissues. In addition, the abnormal vessels frequently leak and rupture, causing further injury to the tissues. To this point, AVMs have not been seen as aberrations of lumen formation, and it is poorly understood how endothelial differentiation is linked to lumen formation in AVMs. Here, we demonstrate that excess endothelial Sry-box 2 (Sox2) alters the transcriptional landscape to induce endothelial-mesenchymal transitions (EndMTs), which cause aberrations in the lumen formation or "lumen disorder" in cerebral AVMs. Limiting EndMTs by suppressing Sox 2 in the cerebral endothelium improves the lumen disorder and in turn cerebral AVMs.

\section{Results}

Sox2 and mesenchymal marker emerge in the endothelium of human cerebral AVMs. To determine the characteristics of ECs in human cerebral AVMs, we examined the expression of documented hallmarks of EndMTs $(17,18,22)$. The results revealed that the expression of the stem cell marker Sox 2 and the mesenchymal marker $\mathrm{N}$-cadherin emerged in the lesions of cerebral AVMs, as determined by immunostaining, flow cytometric analysis, and real-time PCR (Figure 1, A, B, and D). The results also showed that both Sox2 and N-cadherin colocalized with the endothelial marker CD31 (Figure 1, A and B). HTB133, a breast cancer cell line with high expression of $\mathrm{N}$-cadherin, was used as a positive control for N-cadherin staining (Figure 1A; ref. 23). Furthermore, our 


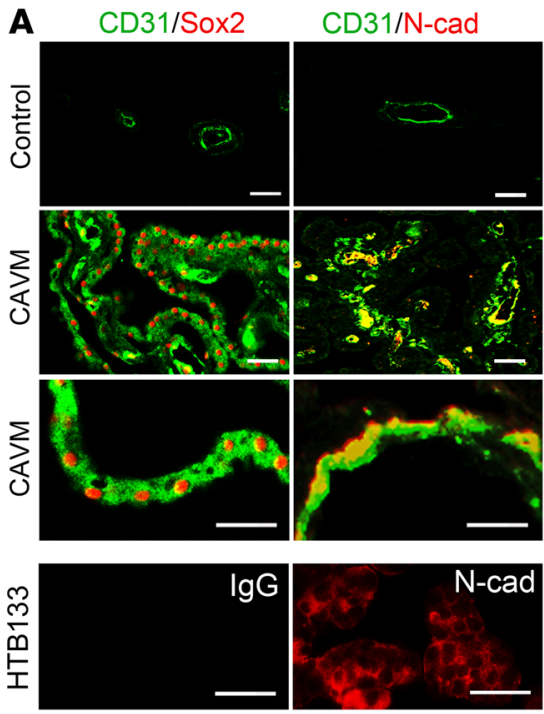

$\mathbf{E}$

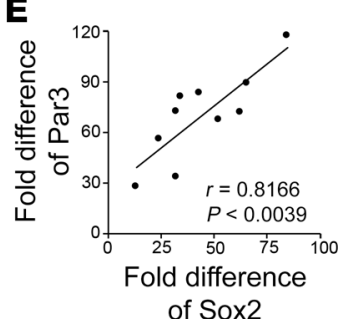

of Sox2
$\mathbf{F}$

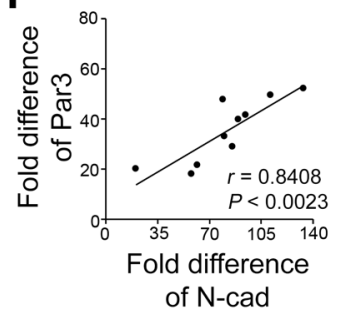

B

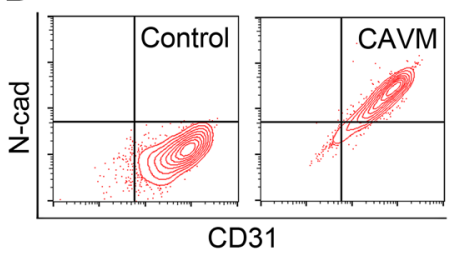

C

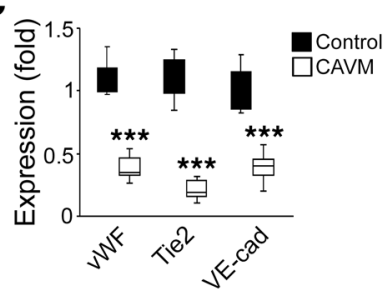

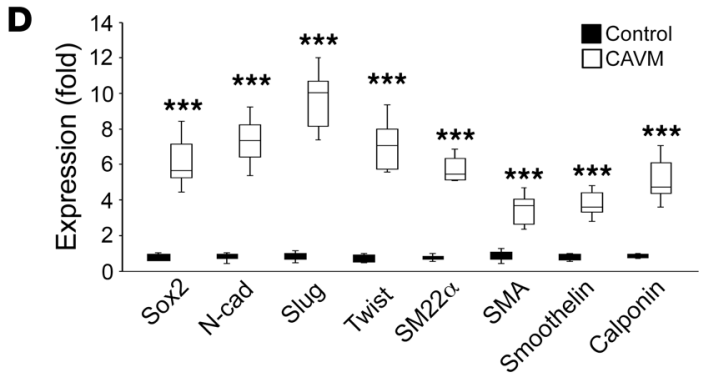

G

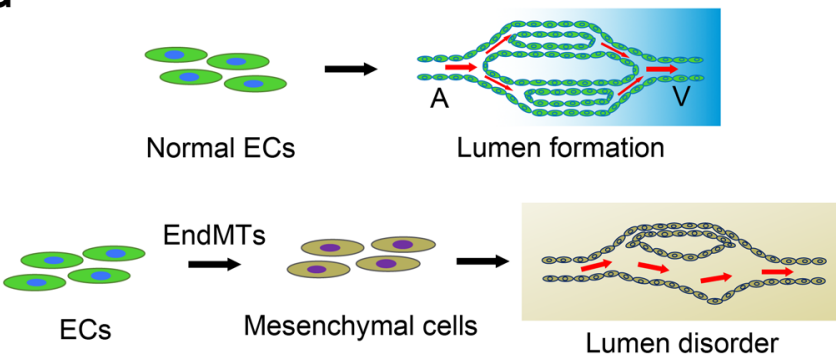

Figure 1. EndMTs correlate with lumen disorder in human cerebral AVMs. (A) The expression of Sox2 and N-cadherin ( $\mathrm{N}$-cad) in lesions of cerebral AVMs (CAVM) was examined by immunofluorescence staining $(n=5)$. CD31 (green) was used as a marker for the endothelium. Normal cerebral vessels were used as controls. HTB133 cells were used as positive controls for the anti-N-cadherin antibodies (bottom). Scale bars: $100 \mu \mathrm{m}$. (B) Flow cytometric analysis of expression of N-cadherin in CD31-positive cells isolated by fluorescence-activated cell sorting $(n=3)$. (C and $\mathbf{D})$ Expression of endothelial and mesenchymal markers in lesions of cerebral AVMs, as shown by real-time PCR $(n=5)$. SMA, smooth muscle actin; VE-cad, VE-cadherin. Data were analyzed by Student's $t$ test. Data are shown by box and whisker plots. The bounds of the boxes represent upper and lower quartiles. The lines in the boxes represent the median, and the whiskers represent the maximum and minimal values. ${ }^{* *} P<0.001$. (E and $\mathbf{F}$ ) Correlation between the fold increase in expression of the lumen-associated gene Par3 and (E) Sox2 and $(\mathbf{F}) \mathrm{N}$-cadherin $(n=10)$. (G) Schematic diagram: ECs with EndMTs cause lumen disorder.

real-time PCR results showed an induction of the mesenchymal markers Slug, Twist, SM22 $\alpha$, smooth muscle actin, calponin, and smoothelin (Figure 1D) and a reduction of the endothelial markers vWF, Tie2, and VE-cadherin (Figure 1C) in cerebral AVMs, suggesting that the ECs in cerebral AVMs are subject to mesenchymal transitions. We examined the relationship between these markers and the lumen formation in human cerebral AVMs. We performed correlation analysis to assess the expression of Sox 2 and N-cadherin with that of the lumen-associated gene Par3. The results showed strong positive correlations between excess Sox2, N-cadherin, and Par3 (Figure 1, E and F), pointing to the possibility that excess Sox2 induces EndMTs that lead to disruptions in lumen formation and cerebral AVMs (Figure 1G).

Limiting endothelial Sox2 improves lumen formation and cerebral AVMs. We investigated the role of Sox2 in cerebral AVMs using the matrix Gla protein null $\left(\mathrm{Mg}^{-/-}\right)$mouse, a model of cerebral AVMs (2). At 4 weeks of age, $M g p^{-/-}$mice develop severe cerebral AVMs with enlarged vessels and direct connections between arteries and veins (2). We examined the time course of Sox2 expression in cerebral ECs isolated from the $M g p^{-/-}$mice between P2 and P30. The results revealed an increase in Sox2 expression in the $M g p^{-/-}$cerebral ECs, with a pattern similar to that seen with the expression of MGP in WT $\left(\mathrm{Mgp}^{+/+}\right)$control cells (Figure 2, A and B). The presence of cerebral AVMs with high expression of Sox 2 allowed us to use the $\mathrm{Mgp}^{-/-}$mice to test the hypothesis that excess Sox2 disrupts EC differentiation and causes abnormal lumens in cerebral AVMs.

We selectively limited Sox 2 expression in $M g p^{-/-}$ECs by breeding $M g p^{+/-}$and $C d h 5^{\text {cre }} S o x 2^{f / W T}$ mice. The results of real-time PCR and immunostaining showed that the elevated Sox2 expression was abolished in the cerebral ECs of $C d h 5^{\text {rre }} S o x 2^{f / W T} M g p^{-/-}$mice (Figure 2, C and D), confirming that the Cdh5-Cre limited Sox2 expression in $M g p^{-/-}$ECs. Immunostaining for the endothelial marker

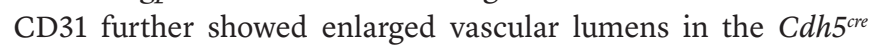

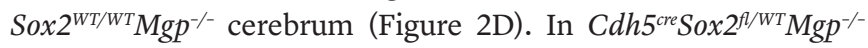
mice, depletion of Sox 2 decreased the lumen size to a range comparable to that of mice with MGP (Figure 2D). The cerebral AVMs were characterized by enlarged vessels, niduses of enlarged and tortuous blood vessels, and abnormal direct connections between arteries and veins (Figure 2E), as previously described for the $M g p^{-/-}$ 

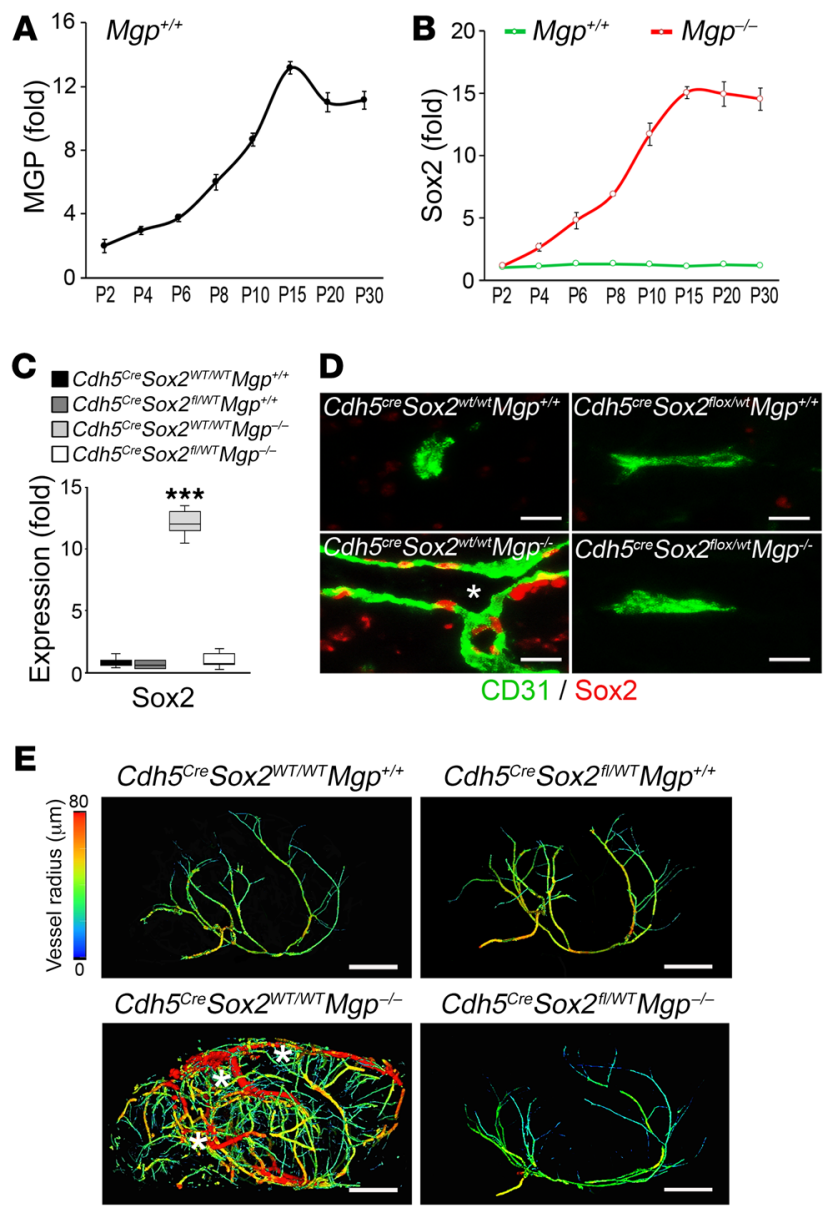
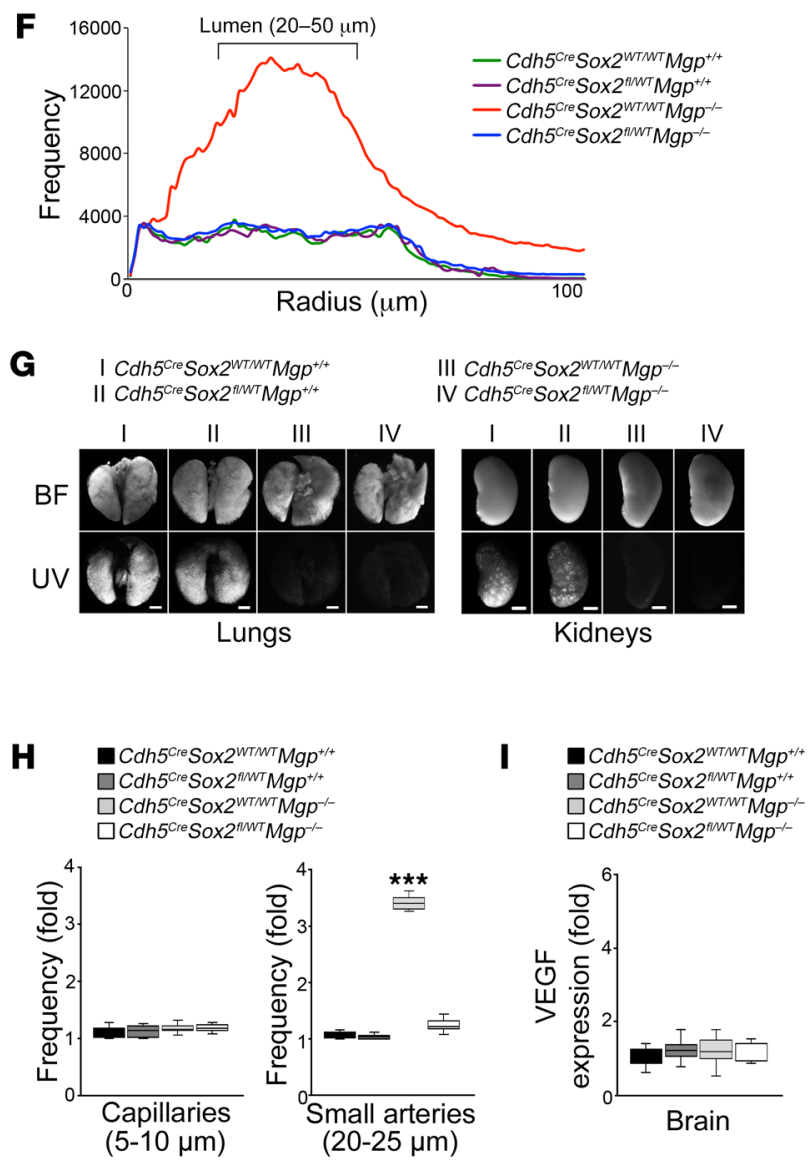

Figure 2. Suppression of Sox2 reduces cerebral AVMs. (A) Time-course expression of MGP in cerebral ECs of WT mice $(n=6)$. (B) Time-course expression of

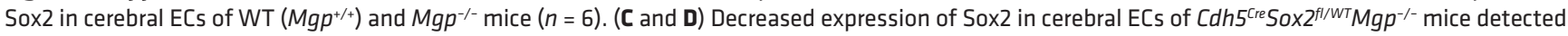
by real-time (C) PCR and (D) immunostaining $(n=5)$. CD31 (green) was used as an endothelial marker. Scale bars: $100 \mu$ m. Asterisk indicates arteriovenous shunt with enlarged lumen. (E) $\mu \mathrm{CT}$ images of the cerebral vasculature in mice with colors reflecting the vessel radii $(n=3)$. Scale bar: $1 \mathrm{~mm}$. (F) Frequency of vessels with different radii in the cerebrum of mice detected by $\mu \mathrm{CT}$ imaging $(n=3)$. (G) Arteriovenous shunting examined by UV-fluorescent microsphere passage in lungs and kidneys $(n=8)$. BF, bright field. (H) Frequency of capillaries ranging from 5 to $10 \mu \mathrm{m}$ and small arteries ranging from 20 to $25 \mu \mathrm{m}$ in the cerebrum of mice examined by $\mu \mathrm{CT}$ imaging $(n=3)$. (I) Expression of VEGF in brain, as determined by real-time PCR $(n=5)$. Data shown in C, H, and I were analyzed by 1-way ANOVA with Tukey's multiple comparisons test. Data are shown by box and whisker plots. The bounds of the boxes represent upper and lower quartiles. The lines in the boxes represent the median, and the whiskers represent the maximum and minimal values. ${ }^{* * *} P<0.001$.

mice (2). We also examined the brain vasculature of $C d h 5^{\text {cre }}$ So $x 2^{f / W T} M g p^{-/}$mice by $\mu \mathrm{CT}$ imaging, which revealed a significant improvement in lumen formation and cerebral AVMs (Figure 2, E and F). Radius analysis in $C d h 5^{\text {cre }} \operatorname{Sox} 2^{W T / W T} \mathrm{Mgp}^{-/-}$mice showed an increased frequency of brain vessels with lumen sizes between 20 and $50 \mu \mathrm{M}$, which identified cerebral AVMs (2). Suppressing Sox2 diminished this increase in the $C d h 5^{\text {cre }} S o x 2^{f / W T} M g p^{-/-}$mice (Figure $2 \mathrm{~F}$ ), further confirming that Sox2 suppression improved lumen formation and reduced cerebral AVMs.

For comparison, we examined the $C d h 5^{\text {cre }} S o x 2^{f / W T} M g p^{-/-}$mice for pulmonary and renal AVMs. Such AVMs are known to coexist with cerebral AVMs in $M g p^{-/-}$mice $(2,24)$. We utilized $15 \mu \mathrm{m}$ GFP-labeled microspheres, which are retained in normal capillary networks, but washed away if arteriovenous shunts are present (24). The results showed that the endothelial-specific deletion of Sox2 had no effect on the pulmonary and renal AVMs in Cdh5 $5^{\text {cre }}$ So $\times 2^{f / W T} M g p^{-/-}$mice (Figure $2 \mathrm{G}$ ), confirming that cerebral AVMs are mechanistically different from pulmonary and renal AVMs.
We also examined the formation of cerebral capillaries, in which the lumen size ranged from 5 to $10 \mu \mathrm{m}$, by using $\mu \mathrm{CT}$. The frequency of capillaries did not differ between mice with and without MGP, and depletion of Sox2 had no apparent effect on vessels with lumen size 5 to $10 \mu \mathrm{m}$ when compared with the effect on the vessels with lumen size 20 to $25 \mu \mathrm{m}$ (Figure $2 \mathrm{H}$ ). Altered expression levels of VEGF has previously been reported in capillary rarefaction (25). Therefore, we examined the cerebral expression of VEGF and found no significant changes in VEGF between WT and $M g p^{-/-}$mice, with or without depletion of Sox 2 (Figure 2I), suggesting that lumen disorder in these mice does not involve capillaries.

To assess for possible EndMTs in the cerebral endothelium, we isolated CD31-positive cerebral ECs from $M g p^{-/-}$and $M g p^{+/+}$ mice (Figure $3 \mathrm{~A}$ ) and examined the expression of mesenchymal and endothelial markers. The result showed an increase in the mesenchymal markers CD10, CD44, CD71, c-kit, CD90, Sca1, Klf4, Slug, N-cadherin, Twist, SM22 $\alpha$, smooth muscle actin, calponin, smoothelin, and c-Myc, but a decrease in the endothelial 
A
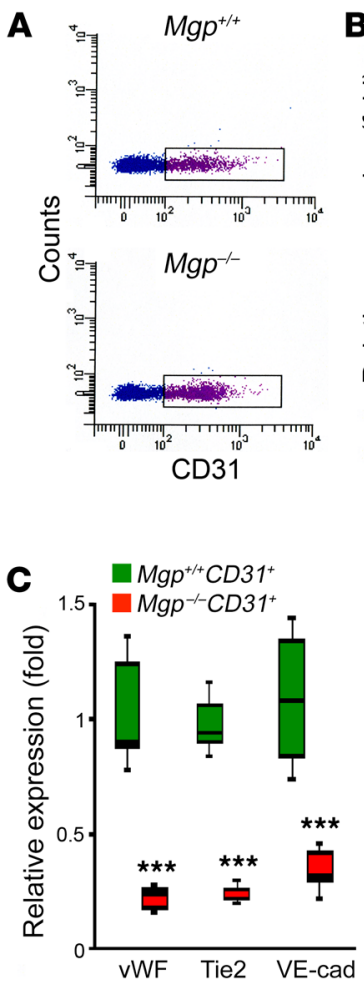

F

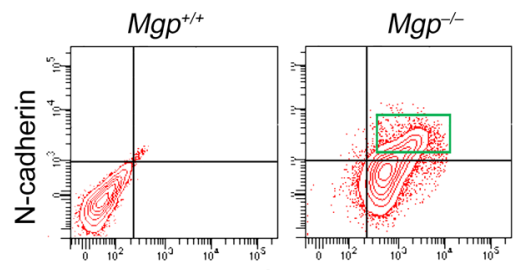

Sox2

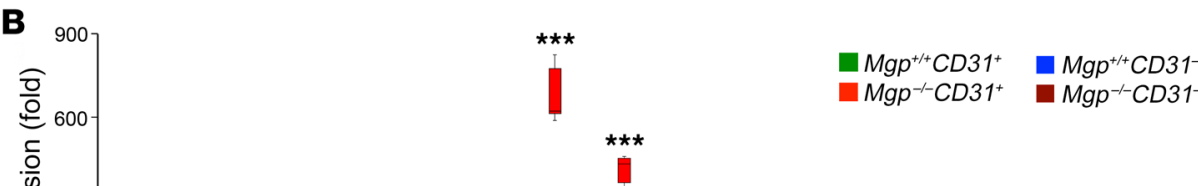

**

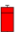

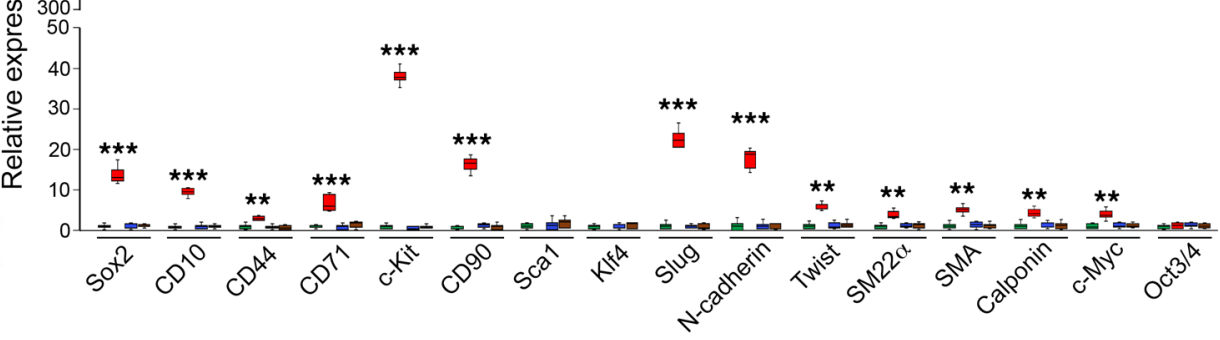

D

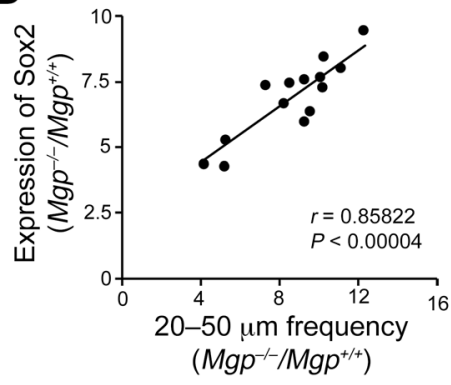

E

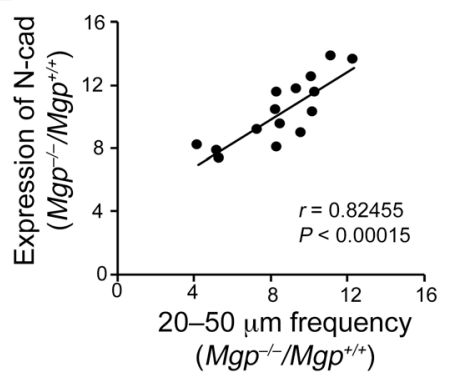

G

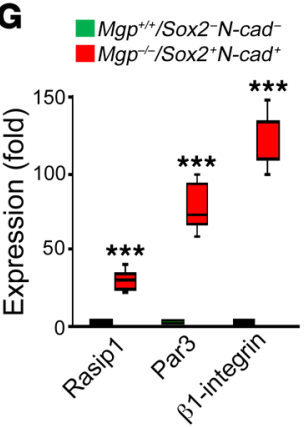

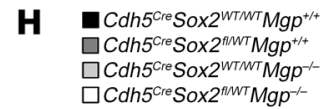

I

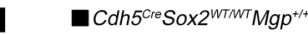

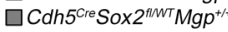
$\square C d h 5^{\text {Cre Sox }}{ }^{\text {WTWT Mgp }}{ }^{-1}$

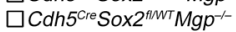
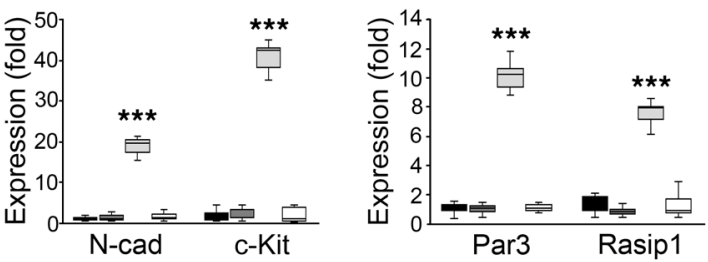

Figure 3. Excess Sox2 alters EC differentiation to cause lumen disorder in the cerebral vasculature of $\mathbf{M g p}^{-/-}$mice. (A) The population of CD31-positive ECs isolated from the cerebra of $\mathrm{Mgp}^{+/+}$and $\mathrm{Mgp}^{-/-}$mice. (B and $\mathbf{C}$ ) Expression of mesenchymal and stem cell markers (B) and endothelial markers (C) in different cell populations isolated from the cerebra of $\mathrm{Mgp}^{+/+}$and $\mathrm{Mgp}^{-/-}$mice $(n=5)$. ( $\mathbf{D}$ and $\left.\mathbf{E}\right)$ Correlation between increased Sox2 and $\mathrm{N}$-cadherin and increased frequency of vessels with radii ranging from 20 to $50 \mu \mathrm{m}(n=15)$. (F) Flow cytometric analysis of cerebral ECs isolated from Mgp $\mathrm{p}^{+/+}$and $\mathrm{Mgp}^{-/-}$mice $(n=3)$. (C) High expression of the lumen-associated genes Rasip1, Par3, and $\beta 1$-integrin in Sox2 and N-cadherin double-positive cerebral ECs isolated from $\mathrm{Mgp}^{-/-}$mice $(n=5) . \mathrm{Mgp}^{+/+}$mice were used as controls. $(\mathbf{H}$ and $\mathbf{I})$ Decreased expression of mesenchymal markers $\mathrm{N}$-cadherin and c-kit $(\mathbf{H})$ and

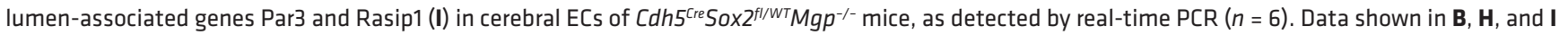
were analyzed by 1-way ANOVA with Tukey's multiple comparisons test. Data shown in $\mathbf{C}$ and $\mathbf{G}$ were analyzed by Student's $t$ test. Data are shown by box and whisker plots. The bounds of the boxes represent upper and lower quartiles. The lines in the boxes represent the median, and the whiskers represent the maximum and minimal values. ${ }^{* *} P<0.01 ;{ }^{* *} P<0.001$.

markers vWF, Tie2, and VE-cadherin in $M g p^{-/}$ECs (Figure 3, B and C), suggesting ongoing EndMTs. The stem cell marker Oct3/4 showed no change in the $M g p^{-/}$ECs (Figure 3B). We also examined the expression of the lymphatic endothelial markers Prox1, Foxc2, Sox18, and Lyve1, but these genes were not induced in the $M g p^{-/-}$cerebral ECs (Supplemental Figure 1; supplemental material available online with this article; https://doi.org/10.1172/ JCI125965DS1), suggesting that cerebral AVMs in $\mathrm{Mgp}^{-/ /}$mice did not adopt lymphatic characteristics.

We then assessed the relationship between the expression of Sox 2 and N-cadherin and the frequency of 20 to $50 \mu \mathrm{M}$ vessels.
The analysis showed that the induction of Sox 2 and N-cadherin strongly correlated with the increased frequency of 20 to $50 \mu \mathrm{M}$ vessels (Figure 3, D and E), suggesting that the disordered lumen is related to alterations in endothelial differentiation. We further isolated cerebral ECs coexpressing Sox 2 and N-cadherin from $M g p^{-/}$mice (Figure 3F), and examined the lumen-associated genes Rasip1, Par3, and $\beta_{1}$ integrin. We found that all these genes were significantly increased in the Sox $2^{+} \mathrm{N}-$ cadherin $^{+}$cerebral ECs (Figure 3G), suggesting that EndMTs in cerebral ECs cause lumen disorder. We also examined the expression of mesenchymal and stem cell markers and lumen-associated genes in the cerebral 

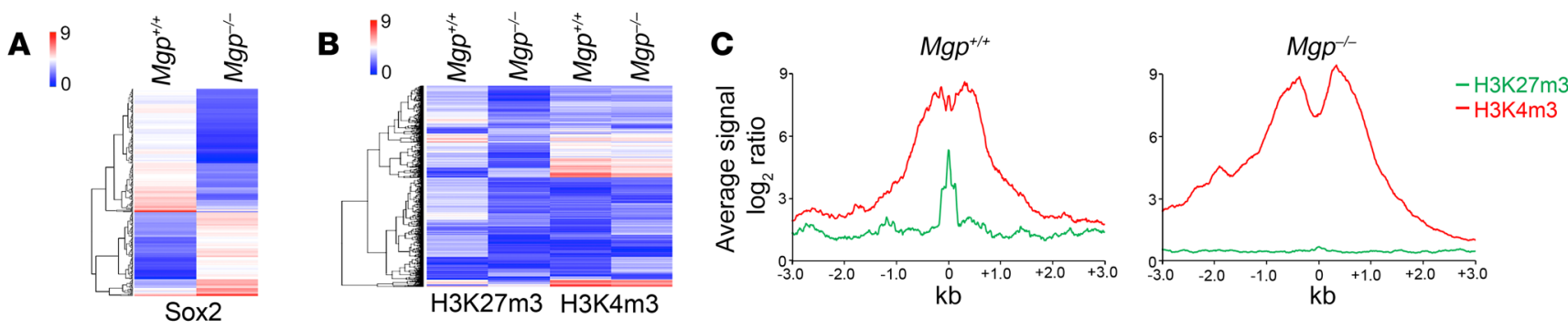

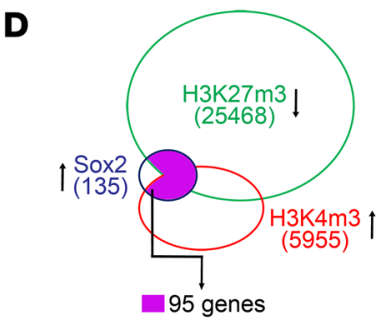

E
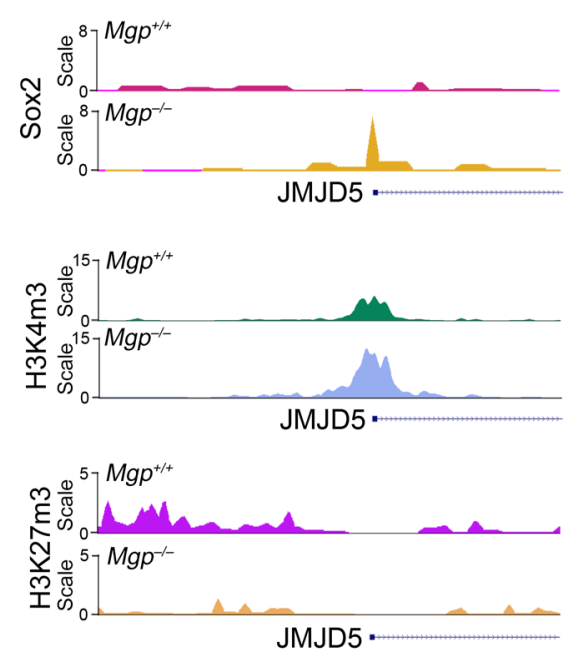

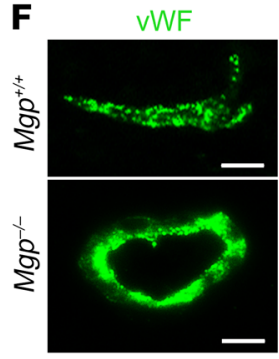

JMJD5
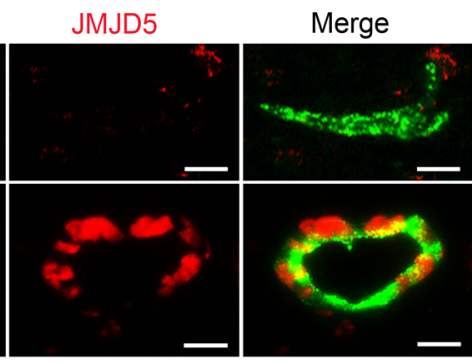

G

H

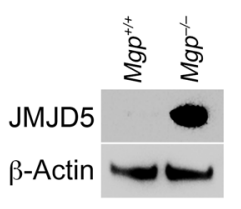

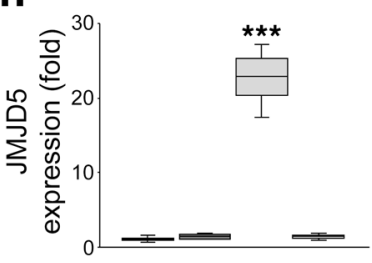

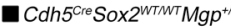
$\square C d h 5^{\text {Cre Sox }} 2^{\text {flWT }} M_{g p^{+/ t}}$

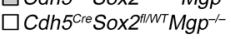

Figure 4. Excess Sox2 alters the transcriptional landscape of Mgp $^{-/-}$cerebral ECs and activates JMJD5. (A) Heatmap showing the densities at Sox2-binding sites in cerebral ECs obtained from ChIP-Seq data. Blue indicates a low level and red a high level. (B) Heatmap showing occupancy of H3K27m3 and $\mathrm{H} 3 \mathrm{~K} 4 \mathrm{~m} 3$ in cerebral ECs, as obtained from ChIP-Seq data. Blue indicates a low level and red a high level. (C) Profile of occupancy of H3K27m3 and H3K4m3 around Sox2-binding sites $\pm 3 \mathrm{~kb}$. (D) Gene ontology analysis showing the genes with increased Sox2 binding and changes of bivalent marks in regulatory regions in cerebral ECs. (E) Plots of Sox2, H3K4m3, and H3K27m3 at JMJD5 loci in Mgp ${ }^{+/+}$and Mgp $^{-/-}$cerebral ECs. (F and $\mathbf{C}$ ) Expression of JMJD5 in Mgp ${ }^{+/+}$ and $\mathrm{Mgp}^{-/-}$cerebral ECs as shown by $(\mathbf{F})$ immunostaining and $(\mathbf{C})$ immunoblotting $(n=5)$. Scale bars: $100 \mu \mathrm{m}$. (H) Suppression of Sox2 abolished the increase of JMJD5 in $\mathrm{Mgp}^{-/-}$cerebral ECs, as detected by real-time PCR $(n=5)$ and analyzed by 1-way ANOVA with Tukey's multiple comparisons test. Data are shown by box and whisker plots. The bounds of the boxes represent upper and lower quartiles. The lines in the boxes represent the median, and the whiskers represent the maximum and minimal values. ${ }^{* *} P<0.001$.

ECs of the $C d h 5^{\text {cre }} S o x 2^{f / W T} M g p^{-/-}$mice by real-time PCR. The results showed that the induction of the mesenchymal and stem cell markers as well as the lumen-associated genes was abolished in the $M g p^{-/-}$cerebral ECs by the endothelial-specific deletion of Sox2 (Figure 3, H and I). Together, the results suggested that excess Sox 2 triggers cerebral ECs to undergo mesenchymal transitions and cause lumen disorder in cerebral AVMs.

Since MGP is a BMP inhibitor (26), we determined whether depletion of Sox 2 altered BMP activity by examining the phosphorylation of mothers against decapentaplegic homolog $1 / 5 / 8$ (pSMAD1/5/8) in cerebral ECs. The results showed no differences in pSMAD1/5/8 levels between $C d h 5^{\text {cre }} S o x 2^{W T / W T} M g p^{-/-}$and $C d h 5^{\text {cre }}$ So $\times 2^{f / W T} M g p^{-/-}$cerebral ECs, as determined by immunoblotting
(Supplemental Figure 2A), suggesting that depletion of Sox2 does not directly regulate BMP signaling.

Excess Sox 2 alters the transcriptional landscape in $\mathrm{Mgp}^{-/-}$cerebral ECs and induces JMJD5. Sox2 transcriptional activity is involved in developmental processes, cell reprograming, and cell-cell transdifferentiation (22, 27-32). Therefore, we examined the transcriptional activity of excess Sox 2 in $M g p^{-/}$cerebral ECs using ChIP with parallel DNA sequencing (ChIP-Seq). $M g p^{+/+}$cerebral ECs were used as controls. The results revealed significant changes in Sox2-enriched peaks in the $\mathrm{Mgp}^{-/-}$cerebral ECs and increases in Sox2 DNA binding in the promoter region of 135 targeted genes (Figure $4 \mathrm{~A}$ ). To evaluate the chromatin state in the presence of excess Sox2, we performed ChIP-Seq to examine bivalent marks including trimethylated 
A

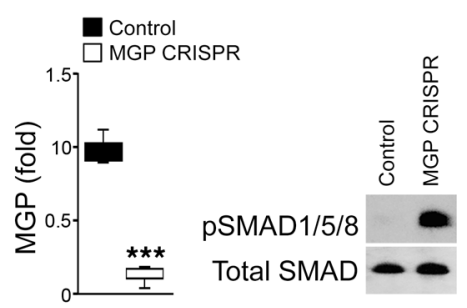

B

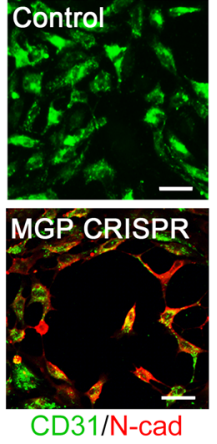

C

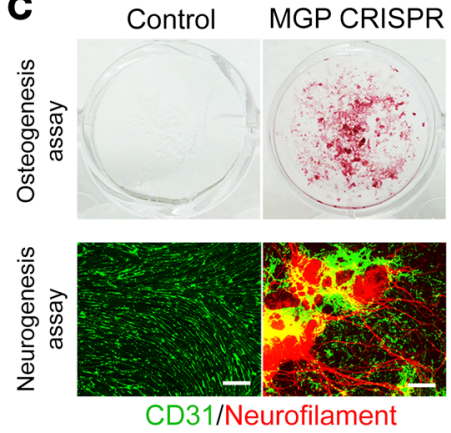

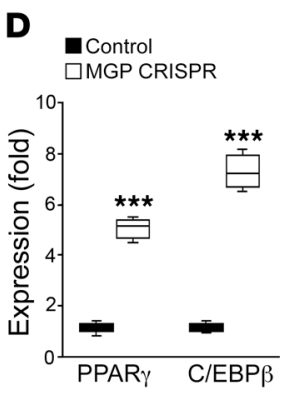

(Adipogenesis assay)
E

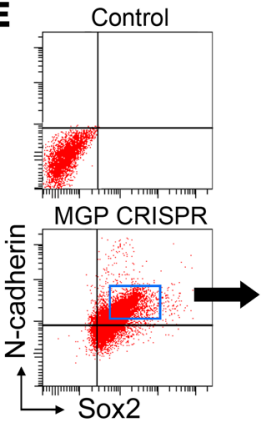

$\mathbf{F}$

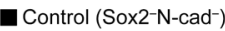
$\square$ MGP CRISPR $\left(\mathrm{Sox}^{+} \mathrm{N}-\mathrm{cad}^{+}\right)$

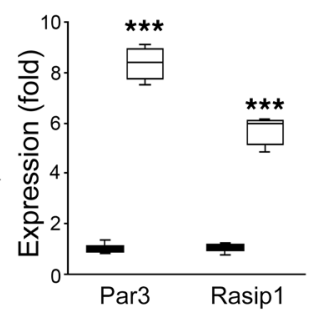

G

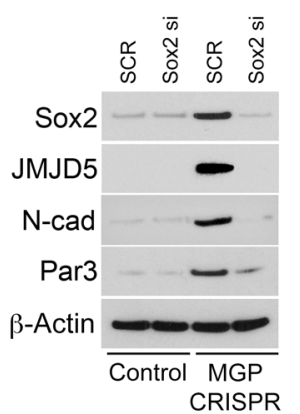

H

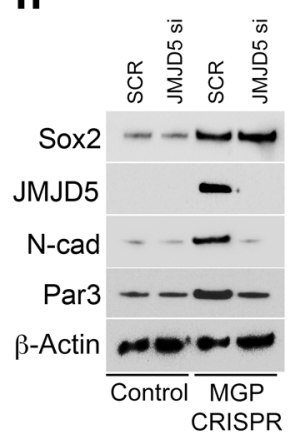

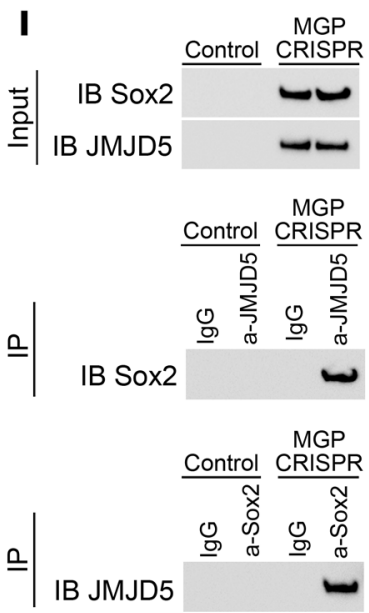

J

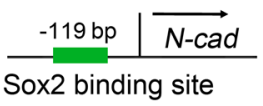

L
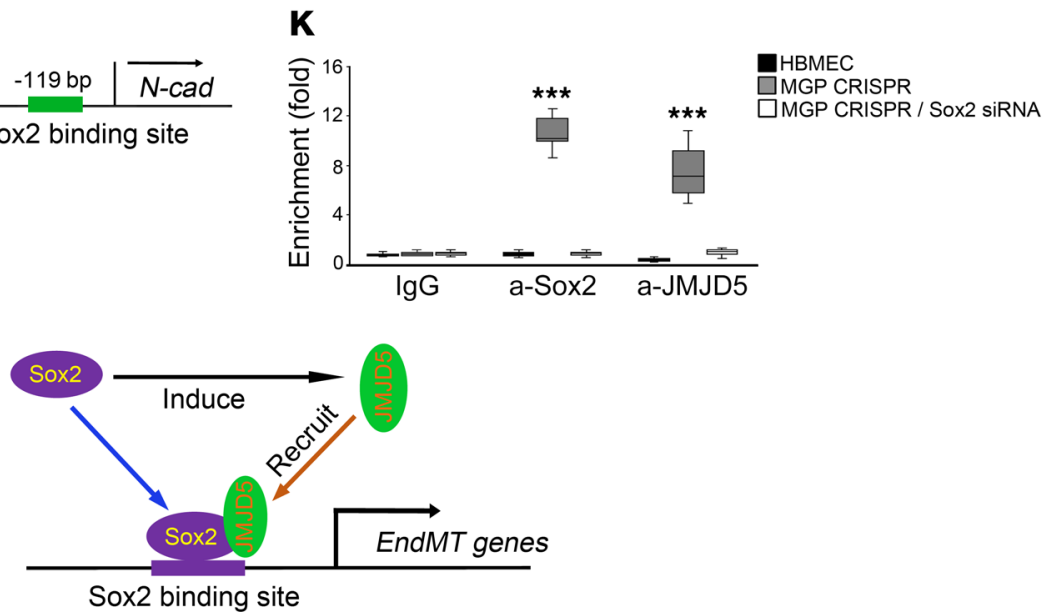

Figure 5. Sox2/JMJD5 prompts ECs to undergo mesenchymal transitions, resulting in lumen disorder. (A) MCP expression and pSMAD1/5/8 levels in HBMECs after depletion of MCP using CRISPR/Cas9 (MGP CRISPR) $(n=5)$. (B) Coimmunofluorescent staining of CD31 (green) and N-cadherin (red) in MCP CRISPR cells. HBMECs were used as controls $(n=10)$. Scale bars: $100 \mu \mathrm{m}$. (C) Alizarin red staining of MGP CRISPR cells after treatment with osteogenic media (top). Coimmunofluorescent staining of CD31 (green) and neurofilament (red) in MCP CRISPR cells after treatment with neurogenic media (bottom). HBMECs were used as controls $(n=3)$. Scale bars: $100 \mu \mathrm{m}$. (D) Expression of the adipogenic markers PPAR $\gamma$ and C/EBP in MGP CRISPR cells after treatment with adipogenic media $(n=3)$. (E) Flow cytometric analysis of MCP CRISPR cells. HBMECs were used as controls $(n=3)$. (F) Increased expression of the lumen-associated genes Par3 and Rasip1 in Sox2 and N-cadherin double-positive cells isolated from MGP CRISPR cells $(n=6)$. (G) Suppression of Sox2 expression by siRNA (si) decreases expression of JMJD5, N-cadherin, Par3, and Rasip1 in MCP CRISPR cells, as shown by immunoblotting ( $n=6)$. (H) Limiting JMJD5 expression by siRNA decreases the expression of N-cadherin, Par3, and Rasip1 in MGP CRISPR cells, as shown by immunoblotting ( $n=3$ ). (I) Coimmunoprecipitation of Sox2 and JMJD5 from lysed MCP CRISPR cells as shown by immunoblotting. HBMECs were used as controls $(n=3)$. (J) Sox2 DNA-binding site in the promoter of the N-cadherin gene. (K) ChIP assay of Sox2 DNA-binding in the promoter of N-cadherin using enriched genomics DNA from MGP CRISPR cells with or without transfection of Sox2 siRNA. Genomics DNA was enriched by using anti-Sox2 (a-Sox2) or anti-JMJD5 (a-JMJD5) antibodies ( $n=3$ ). (L) Schematic diagram: Sox2 induces and interacts with JMJD5 to induce EndMTs. Data shown in A, D, and F were analyzed by Student's $t$ test. Data shown in K was analyzed by 1-way ANOVA with Tukey's multiple comparisons test. Data are shown by box and whisker plots. The bounds of the boxes represent upper and lower quartiles. The lines in the boxes represent the median, and the whiskers represent the maximum and minimal values. ${ }^{* * *} P<0.001$.

histone $\mathrm{H} 3$ lysine 4 (H3K4me3) associated with active transcription and H3K27me3 associated with closed chromatin. In $\mathrm{Mgp}^{-1-}$ cerebral ECs, the results showed that the deposition of $\mathrm{H} 3 \mathrm{~K} 4 \mathrm{me} 3$ increased in 5955 genes and the deposition of $\mathrm{H} 3 \mathrm{~K} 27 \mathrm{me} 3$ decreased in 25468 genes (Figure 4, B-D), suggesting a marked alteration of the chromatin status and the endothelial transcriptional landscape.

We analyzed the effects of Sox 2 binding on the chromatin state of these genes and identified 95 genes om which excess Sox 2 
A
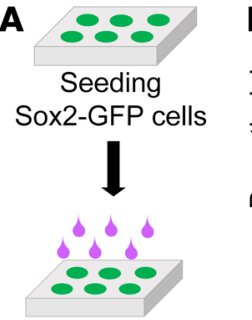

Loading

compound

libraries

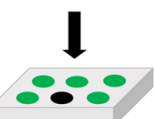

Candidate

repressing

Sox2-GFP

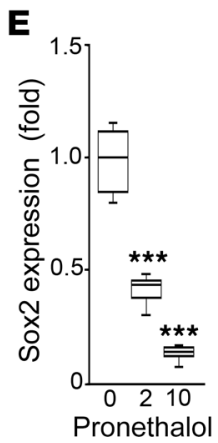

$(u \mathrm{M})$
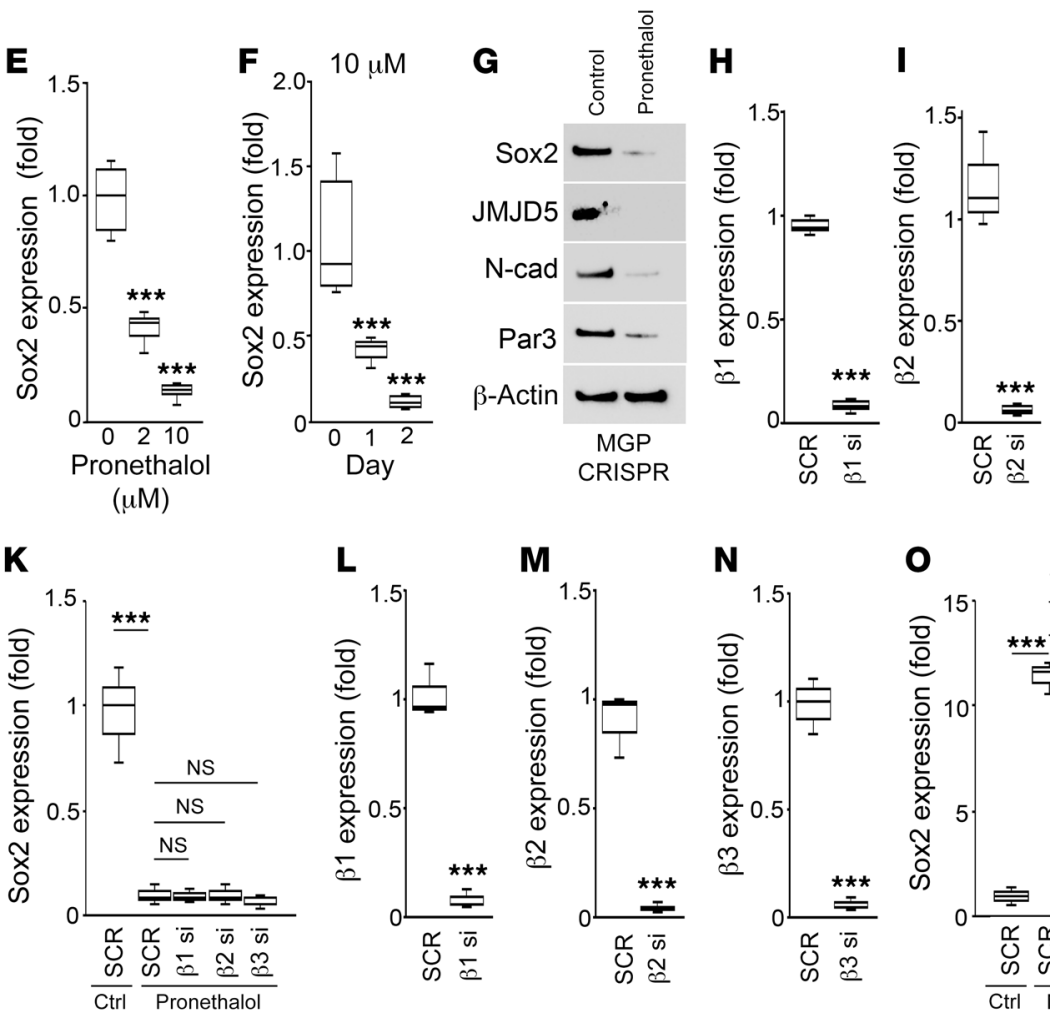

J
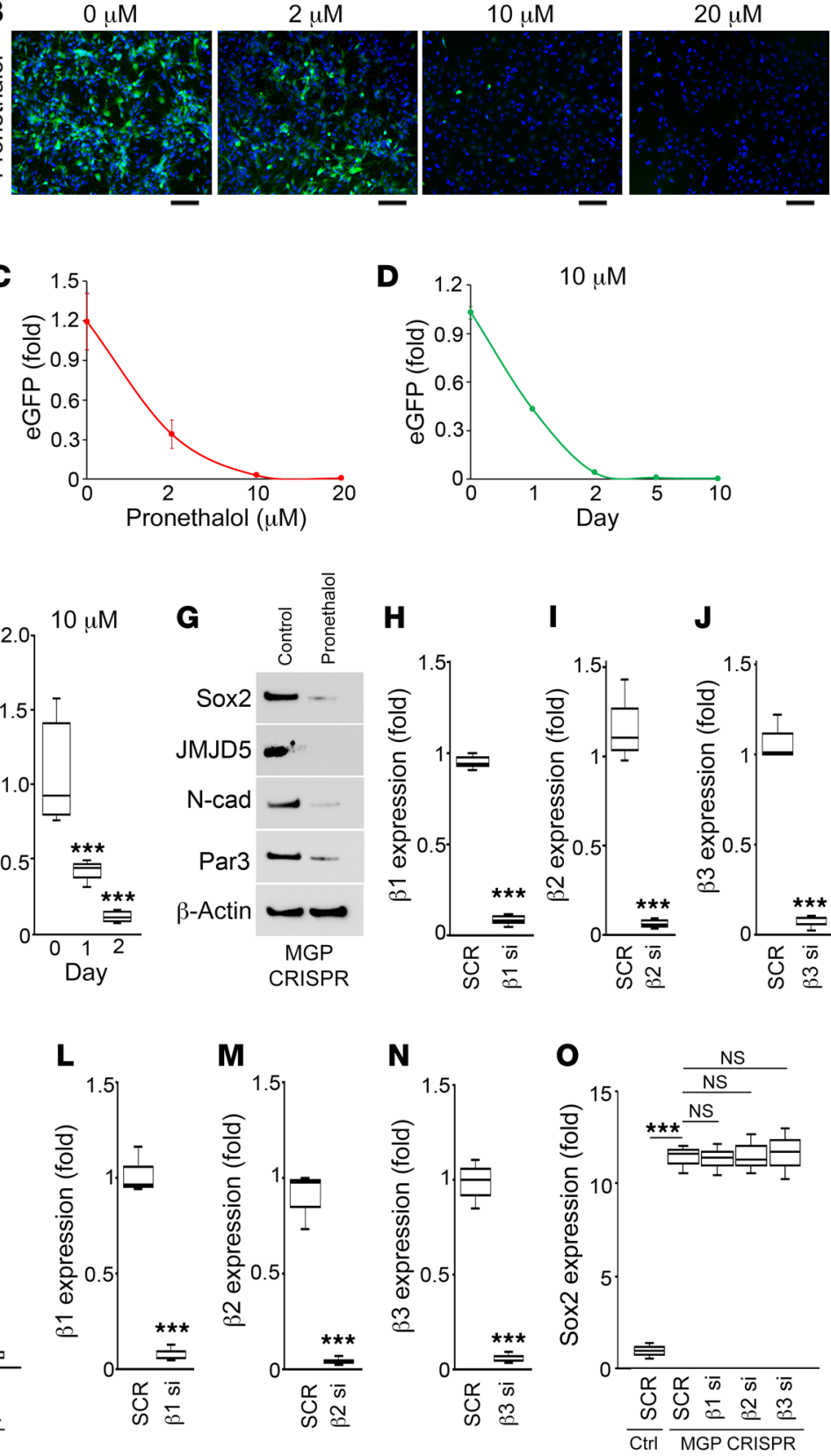

Figure 6. A high-throughput system identifies pronethalol as an inhibitor of Sox2 expression. (A) Schematic diagram of the high-throughput system used for screening candidate compounds that may suppress Sox2 expression in ReNcell VM cells. (B and $\mathbf{C}$ ) Expression of EGFP in ReNcell VM cells after treatment with increasing doses of pronethalol, as (B) detected by fluorescence microscope and (C) quantitated by ImageJ software $(n=5)$. Scale bars: $50 \mu \mathrm{m}$. (D) Time-course expression of EGFP in ReNcell VM cells treated with $10 \mu \mathrm{M}$ pronethalol $(n=5)$. ( $\mathbf{E}$ and $\mathbf{F})$ Dose and time-course expression of Sox2 after treatment with pronethalol in ReNcell VM cells $(n=5)$. (C) Decreased expression of Sox2, JMJD5, N-cadherin, Par3, and Rasip1 in MGP CRISPR cells after treatment with $10 \mu \mathrm{M}$ pronethalol for 48 hours, as shown by immunoblotting $(n=5)$. ( $(\mathbf{H}-\mathbf{J})$ Expression of (H) $\beta 1-$, (I) $\beta 2$ - or (J) $\beta 3$-adrenergic receptors ( $\beta 1, \beta 2$, and $\beta 3$ ) in ReNcell VM cells transfected with siRNA to individual $\beta 1-, \beta 2-$, or $\beta 3$-adrenergic receptors ( $\beta 1$ si, $\beta 2$ si, and $\beta 3 \mathrm{si})(n=5)$. SCR, scrambled siRNA. (K) Expression of Sox2 in ReNcell VM cells treated with pronethalol and transfected with siRNA to individual $\beta 1-, \beta 2-$, or $\beta 3-$ adrenergic receptors $(n=5)$. SCR, scrambled siRNA. (L-N) Expression of (L) $\beta 1^{-,},(\mathbf{M})$ $\beta 2-$, or $(\mathbf{N}) \beta 3$-adrenergic receptors in MGP CRISPR cells transfected with siRNA to individual $\beta 1-, \beta 2-$, or $\beta 3$-adrenergic receptors $(n=5)$. (0) Expression of Sox2 in MGP CRISPR cells treated and transfected with siRNA to individual $\beta 1-, \beta 2-$, or $\beta 3$-adrenergic receptors $(n=5)$. Data shown in $\mathbf{H}-\mathbf{J}$ and $\mathbf{L}-\mathbf{N}$ were analyzed by Student's $t$ test. Data shown in $\mathbf{E}, \mathbf{F}, \mathbf{K}$, and $\mathbf{O}$ were analyzed by 1-way ANOVA with Tukey's multiple comparisons test. Data are shown by box and whisker plots. The bounds of the boxes represent upper and lower quartiles. The lines in the boxes represent the median, and the whiskers represent the maximum and minimal values. ${ }^{* *} P<0.001$. binding increased $\mathrm{H} 3 \mathrm{~K} 4 \mathrm{me} 3$ or decreased H3K27me3 deposition or both in the promoter regions (Figure 4D). Gene ontology analysis and pathway enrichment showed that these genes participate in stem cell pathways and epithelial-mesenchymal cell signaling (Figure 4D), suggesting that excess Sox2 activated signaling pathways for mesenchymal differentiation in $\mathrm{Mgp}^{-/}$cerebral ECs.

We analyzed the ChIP-Seq data and identified a gene called jumonji domain-containing protein 5 (JMJD5), which had increased unique Sox 2 binding in the promoter (Figure $4 \mathrm{E}$ ). The increased occupancy of H3K4me3 and the decreased occupancy of H3K27me3 around the JMJD5 locus showed that these bivalent marks primed the activation of gene expression (Figure $4 \mathrm{E}$ ). We then examined the expression of JMJD5 in $M g p^{-/}$cerebral ECs by immunostaining and immunoblotting, which showed significant increases in JMJD5 expression (Figure 4, F and G). EC-specific
Sox2 deletion abolished the induction of JMJD5 in $C d h 5^{\mathrm{rre}} S o \times 2^{2 / / W T}$ $\mathrm{Mgp}^{-1-}$ cerebral ECs (Figure $4 \mathrm{H}$ ). Together, the results identified JMJD5 as a direct downstream target of Sox 2 in cerebral ECs.

JMJD5 activates mesenchymal differentiation in brain ECs. To determine the role of JMJD5 in EC differentiation and lumen formation, we generated a human brain microvascular EC (HBMEC) line depleted of MGP using the CRISPR/Cas9 approach (Figure $5 \mathrm{~A})$. The cells were referred to as MGP CRISPR cells. Since MGP is a BMP inhibitor (26), the phosphorylation of SMAD1/5/8 was significantly increased in the MGP CRISPR cells (Figure 5A), confirming the efficiency of MGP depletion.

The MGP CRISPR cells showed high expression of $\mathrm{N}$-cadherin as compared with control cells (Figure 5B), suggesting acquired mesenchymal transition. When treated with osteogenic, neurogenic, or adipogenic induction medium, the MGP CRISPR cells responded to 
A

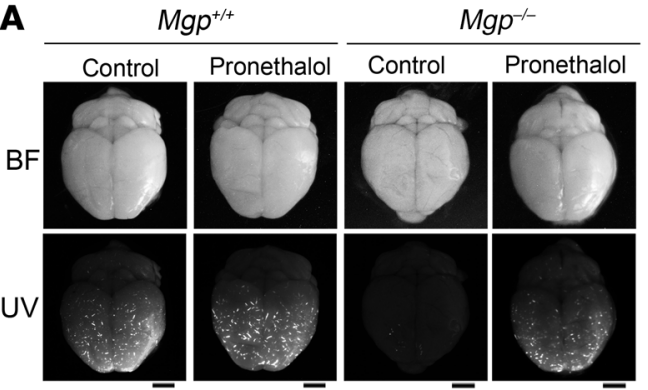

B

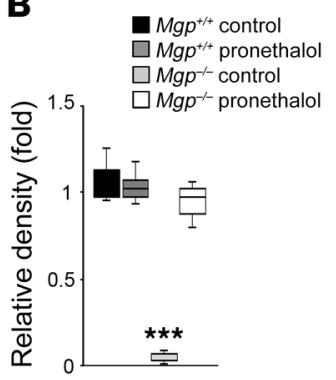

C

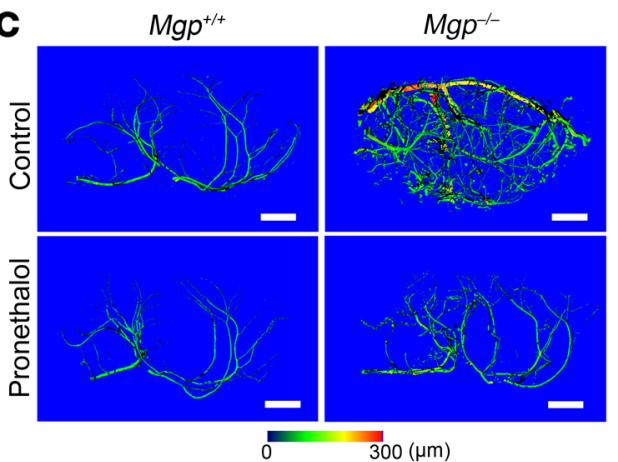

D

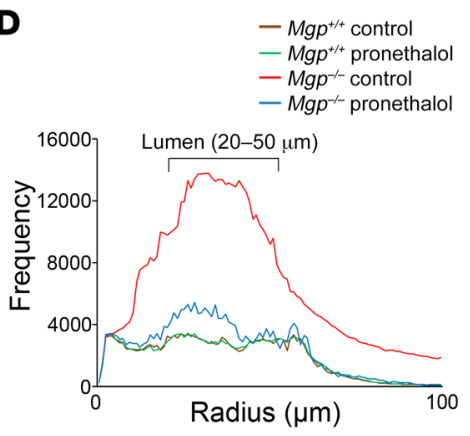

Figure 7. Pronethalol improves cerebral AVMs in $\mathbf{M g p}^{-/-}$mice. (A) Pronethalol decreases arteriovenous shunting in $\mathrm{Mgp}^{-/-}$mice, as demonstrated by UV-fluorescent microsphere injections $(n=5)$. Scale bars: $1 \mathrm{~mm}$. (B) Relative density of retained fluorescent microspheres in the brains of $\mathrm{Mgp}^{+/+}$ and $\mathrm{Mgp}^{-/-}$mice after treatment with pronethalol $(n=5)$. (C) $\mu \mathrm{CT}$ images of the cerebral vasculature with colors reflecting the vessel radii from $\mathrm{Mgp}^{+/+}$ and $\mathrm{Mgp}^{-/-}$mice with or without treatment with pronethalol $(n=3)$. Scale bars: $1 \mathrm{~mm}$. (D) Frequency of vessels with different radii in the cerebra of mice detected by $\mu \mathrm{CT}$ imaging $(n=3)$. (E)

Expression of Sox2, JMJD5, N-cadherin, and Par3 in cerebral ECs isolated from $\mathrm{Mgp}^{+/+}$and $\mathrm{Mgp}^{-/-}$mice that were treated with pronethalol $(n=6)$. ( $F$ and G) Arteriovenous shunting examined by UV-fluorescent microsphere passage in lungs and kidneys $(n=4)$. Data shown in $\mathbf{B}$ and $\mathbf{E}$ were analyzed by 1-way ANOVA with Tukey's multiple comparisons test. Data are shown by box and whisker plots. The bounds of the boxes represent upper and lower quartiles. The lines in the boxes represent the median, and the whiskers represent the maximum and minimal values. ${ }^{* *} P<0.001$.

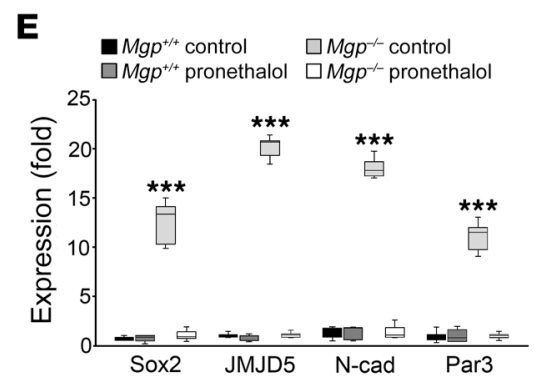

\section{$\mathbf{F}$}
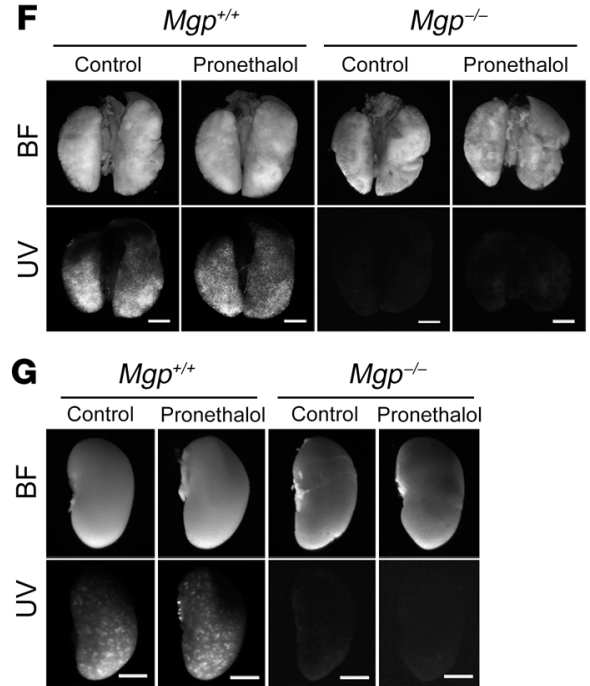

the treatments and showed osteoblastic differentiation and expression of neurogenic markers (Figure 5C) and adipogenic markers (Figure 5D). The results suggest that ECs with EndMTs in cerebral AVMs gain the capacity of mesenchymal differentiation.

Further analysis of the MGP CRISPR cells showed that Sox2 was highly induced, as determined by flow cytometric analysis (Figure 5E), and that the lumen-associated genes Par3 and Rasip1 were increased in Sox ${ }^{+} \mathrm{N}-$ cadherin $^{+}$MGP CRISPR cells (Figure $5 F$ ). We found that the depletion of Sox 2 in the MGP CRISPR cells abolished the induction of JMJD5 (Figure 5G), confirming that JMJD5 is a direct target of Sox2. Sox2 depletion also abolished the induction of N-cadherin, Par3, and Rasip1 (Figure 5G). As expected, depletion of JMJD5 diminished the abnormal expression of $\mathrm{N}$-cadherin, Par3, and Rasip1 (Figure 5H), suggesting that JMJD5 induction by Sox 2 was necessary to cause the changes in EC fate.

To determine whether there is direct protein-protein interaction between Sox2 and JMJD5, we performed coimmuno- precipitation of lysed MGP CRISPR cells using anti-JMJD5 or anti-Sox 2 antibodies, followed by immunoblotting. The results showed that Sox2 and JMJD5 interact in MGP CRISPR cells (Figure 5I). To confirm the interaction, we identified a Sox2 DNAbinding site in the promoter of the N-cadherin gene (Figure 5J) and examined the DNA binding of Sox2 and JMJD5 to this site by using ChIP assays. The specific antibodies to Sox2 or JMJD5 were used to enrich the genomic DNA from MGP CRISPR cells, and normal HBMECs were used as control. The results showed that both Sox2 and JMJD5 pulled down the DNA that contained a Sox2 DNA-binding site in the N-cadherin promoter (Figure $5 \mathrm{~K})$. We further depleted Sox 2 in the MGP CRISPR cells by using siRNA and found that Sox2 depletion abolished both Sox2 and JMJD5 DNA-binding around the Sox2-binding site in the N-cadherin promoter (Figure 5K). The results suggested that Sox 2 not only induces JMJD5, but also recruits and interacts with JMJD5 in the regulation of EndMTs (Figure 5L). 
A
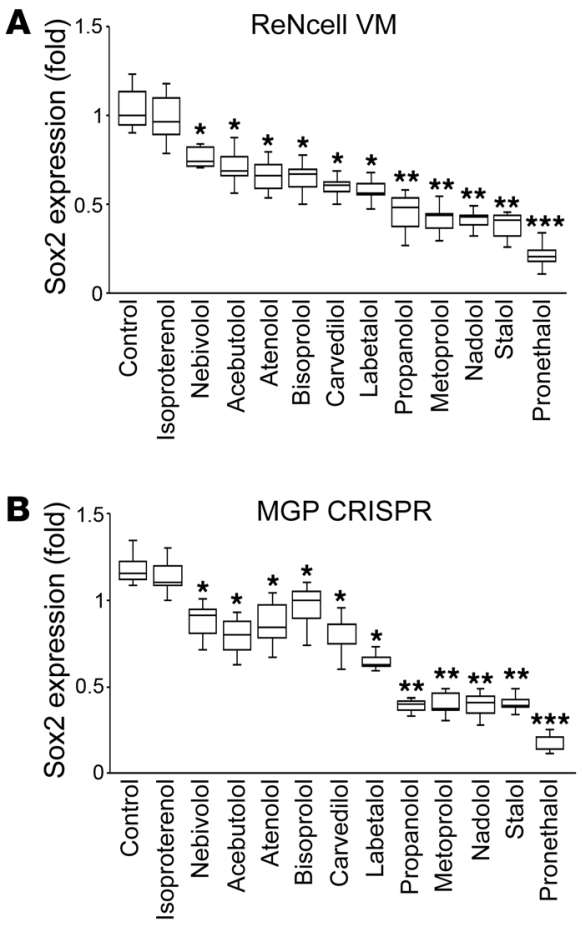

C
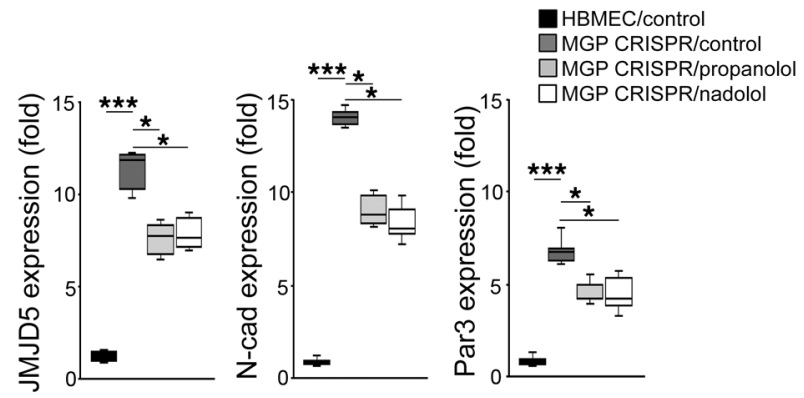

Pronethalol inhibits Sox2 expression, stabilizes EC fate, and improves lumen formation. Our results indicated that excess Sox2 constituted a key factor in the development of cerebral AVMs and might be a target for AVM therapies. Therefore, we explored whether chemical compounds could inhibit Sox 2 expression and improve cerebral AVMs, which might signify potential for clinical translation. To identify chemical compounds that repress Sox2 expression, we created a high-throughput robotic model by using the ReNcell VM cell line (Figure 6A). The ReNcell VM cells are a human neural progenitor cell line, in which Sox 2 is highly and consistently expressed (Figure 6B; ref. 33). We chose the ReNcell VM cells as the primary cells for the high-throughput system because of their cellular stability and easy handling in large-scale tissue culture. The low number of cerebral ECs isolated from the $M g p^{-/-}$mice eliminated the use of these cells, and easily altered plasticity also ruled out the MGP CRISPR cells. We integrated Sox 2 promoter-driven EGFP into the ReNcell VM cells (Figure 6B) and screened more than 3000 compounds ranging from natural products to synthesized compounds. The system identified pronethalol as a compound that repressed EGFP expression in a dose- and time-dependent manner (Figure 6, B-D). We treated the ReNcell VM cells with pronethalol and showed that $10 \mu \mathrm{M}$ pronethalol reduced Sox 2 expression to less than $10 \%$ after 2 days of treatment (Figure 6, E and F).
Figure 8. $\beta$-Adrenergic antagonists decrease Sox 2 expression and EndMTs to improve lumen formation. (A and $\mathbf{B}$ ) Expression of Sox 2 in ReNcell VM cells (A) or MGP CRISPR cells (B) treated individually by $\beta$-antagonists or agonist as determined by real-time PCR $(n=6)$. (C) Expression of JMJD5 (left), N-cadherin (middle), and Par3 (right) in MGP CRISPR cells treated with either propranolol or nadolol, as shown by real-time PCR $(n=6)$. Data shown in A, B, and C were analyzed by 1-way ANOVA with Tukey's multiple comparisons test. Data are shown by box and whisker plots. The bounds of the boxes represent upper and lower quartiles. The lines in the boxes represent the median, and the whiskers represent the maximum and minimal values. ${ }^{*} P<0.05 ;{ }^{* *} P<0.01 ;{ }^{* * *} P<0.001$.

To determine whether pronethalol also affected the MGP CRISPR cells, we treated HBMECs and MGP CRISPR cells with 10 $\mu \mathrm{M}$ pronethalol for 2 days. Immunoblotting showed that the treatment abolished the induction of Sox2, JMJD5, N-cadherin, Par3, and Rasip1 in the MGP CRISPR cells (Figure 6G), suggesting that pronethalol is an inhibitor of Sox 2 expression that might stabilize EC fate and lumen formation.

Pronethalol inhibiting Sox 2 expression does not involve $\beta$-adrenergic receptors. To investigate whether pronethalol inhibited Sox 2 expression through the adrenergic signaling pathway, we individually depleted $\beta 1$-, $\beta 2$-, and $\beta 3$-adrenergic receptors in the pronethaloltreated ReNcell VM cells or MGP CRISPR cells using siRNAs. When compared with scrambled siRNA, the selected siRNAs resulted in an $90 \%$ to $95 \%$ decrease in mRNA, as determined by real-time PCR (Figure 6, H-J and L-N). The results showed that the depletion of these receptors had no effect on Sox 2 expression (Figure 6K and Figure 6O), suggesting that pronethalol exerts its effect through other pathways. Our previous studies have demonstrated that BMP induces Sox2 in aortic calcification (22) and also show that BMP increases Notch signaling in cerebral ECs (2). These studies point to the possibility that the crosstalk between BMP and Notch induces Sox 2 and that pronethalol might disrupt this crosstalk to suppress Sox 2 expression.

Pronethalol hydrochloride improves cerebral AVMs. To determine whether pronethalol improved cerebral AVMs in vivo, we treated $M g p^{-/-}$mice with $0.15 \mathrm{mg} / \mathrm{g}$ pronethalol daily. After 14 days of treatment, we first examined the cerebral AVMs using the injection of GFP-labeled microspheres. The results showed that the microspheres were retained in the brain tissues of $\mathrm{Mgp}^{-/-}$mice that had been treated with pronethalol (Figure 7, A and B), suggesting that pronethalol improved the cerebral capillary network. We also examined the brain vasculature using $\mu \mathrm{CT}$ imaging. The results revealed a significant improvement of the cerebral AVMs in $\mathrm{Mgp}^{-/-}$ mice treated with pronethalol (Figure 7C). Analysis of the lumen radius showed a decrease in the frequency of 20 to $50 \mu \mathrm{m}$ vessels (Figure 7D). We also isolated $M g p^{-/-}$cerebral ECs and found that pronethalol decreased the expression of Sox2, JMJD5, N-cadherin, and Par3 (Figure 7E). However, pronethalol had no effect on the pulmonary and renal AVMs in $M g p^{-/-}$mice, as determined by injection of GFP-labeled microspheres (Figure 7, F and G). Furthermore, pronethalol had no effect on the BMP activity in the $M g p^{-/}$cerebral ECs, as shown by immunoblotting of pSMAD1/5/8 (Supplemental Figure 2B). Together, the results showed that pronethalol limited Sox 2 induction, EndMTs, and lumen disorder in cerebral AVMs. 
Antagonists of $\beta$-adrenergic receptor inhibit Sox 2 expression. To determine whether other antagonists or agonists of the $\beta$-adrenergic receptors affected Sox 2 expression, we treated the ReNcell VM cells individually with $10 \mu \mathrm{M}$ of the $\beta$-agonist isoproterenol or $10 \mu \mathrm{M}$ of the $\beta$-antagonists nebivolol, acebutolol, atenolol, bisoprolol, carvedilol, labetalol, propranolol, metoprolol, nadolol, and sotalol. The results revealed a range of Sox 2 inhibition by the different antagonists (Figure 8A). Propranolol, metoprolol, nadolol, and sotalol were the strongest Sox 2 inhibitors beside pronethalol (Figure 8A). Sox2 expression was not affected by the $\beta$-agonist isoproterenol (Figure 8A), suggesting again that the $\beta$-adrenergic receptors were not involved in the Sox 2 inhibition. We also treated MGP CRISPR cells with the same set of $\beta$-antagonists and agonist, and found a similar range of Sox 2 inhibition (Figure $8 \mathrm{~B}$ ).

To determine whether these $\beta$-antagonists affected the Sox2 target genes, we treated MGP CRISPR cells with $10 \mu \mathrm{M}$ propranolol or nadolol. The results showed that propranolol and nadolol decreased the expression of JMJD5, N-cadherin, and Par3 (Figure $8 \mathrm{C})$, suggesting that these $\beta$-antagonists decrease EndMTs and might improve lumen formation.

\section{Discussion}

Maintenance of endothelial lineage is critical for vascularization and vascular homeostasis. Arranged in a single layer that serve as an interface between the vascular wall and bloodstream, the ECs are constantly influenced by hemodynamic forces and inflammatory stimuli. The environment requires that the endothelium is maintained in an appropriate differentiation stage that is able to support both a normal endothelial life span and the necessary turnover, allowing the ECs to participate in angiogenesis and vascular repair. Without proper differentiation, the ECs may become a driver of pathogenesis leading to vascular disease. Previous studies have shown that ECs with mesenchymal and stem cell-like characteristics contribute to cerebral cavernous malformation, atherosclerosis, and the human genetic disorder fibrodysplasia ossificans progressiva $(14,18,34)$. Moreover, ECs undergoing mesenchymal differentiation have been traced in studies of vascular calcification, where ECs gain multipotency and contribute osteoprogenitors to the calcifying process $(17,22,35,36)$. Here, we show the emergence of mesenchymal stem cell markers in the endothelium of cerebral AVMs, which indicate a change in the endothelial fate through EndMTs. Furthermore, we show that these changes in cell fate cause disruption in the lumen formation, or lumen disorder, in cerebral AVMs.

Differently sized lumens develop in support of the circulating blood and the coordination between the vessels and nearby tissues. The lumen size can range from $10 \mu \mathrm{m}$ in capillaries, allowing only single cells to pass, to centimeters in aorta and its branches. The majority of lumens in the brain vasculature range between 10 and $50 \mu \mathrm{m}$ (Figure 2); these include small arteries, capillaries, and small veins. In the $M g p^{-/-}$mice, a mouse model of AVMs, we document a significant increase in the number of vessels with lumen size 20 to $50 \mu \mathrm{m}$ (Figure 2). These lumen sizes reflect arteriovenous shunts bypassing the $10 \mu \mathrm{m}$ capillaries. We also show that a normalization of the vascular lumen improves cerebral AVMs (Figure 7). We argue that the lumen disorder is an important characteristic of AVMs and that AVMs may be better evaluated by systematically assessing the vascular lumen sizes in tissues.
Located in the innermost layer of the vessel wall, the ECs are important components in lumen formation. Tight EC-EC junctions, EC polarity, and the extracellular matrix surrounding the ECs all contribute to lumen construction (37). Previous studies have identified lumen-associated genes in ECs, such as the polarity proteins $\beta 1$-integrin, Par3, and Rasip1 $(19,21,38)$. In addition, the level of phosphorylated myosin light chain, a downstream target of Rasip1, is an indicator of lumen formation. Lumen construction requires the ECs to respond to demands from the surrounding cells, and abnormally differentiated ECs directly derail lumen formation. Here, we show that a dramatic change in endothelial fate disrupts the expression of lumen-associated genes, resulting in the lumen disorder in cerebral AVMs. Normalizing EC fate by reducing Sox 2 expression corrects the lumen formation and improves AVMs.

EndMTs may directly contribute to vessel enlargement through different mechanisms. First, EndMTs are associated with an increase in proliferation, which has been reported in vascular malformations (14). The increase in cell number is likely to enlarge the luminal surface area and the lumen of the vessel. In the case of MGP deficiency, the proliferation may also be enhanced by increased activity of BMP4 that is normally inhibited by MGP. BMP4 stimulates proliferation of vascular progenitor cells and overall vascular growth $(24,39)$. However, it has also been reported that cell proliferation is not required for the formation of arteriovenous shunts; rath$\mathrm{er}$, what is required is an increase in cell size (40). EndMTs could also enhance this aspect, since EndMTs have been associated with loss of adhesion and increased flexibility in cell shape (18) as well as protease induction and destruction of the basement membrane and the surrounding matrix (22). In addition, flow-responsive signaling pathways may perpetuate and enhance abnormalities linked to EndMTs, creating local conditions that allow the malformations to develop.

The Sox transcription factors are well-known cell-fate regulators, characterized by a DNA-binding high mobility group (HMG) box domain $(41,42)$. Members of Sox family, such as Sox7, Sox17, and Sox18, constitute important factors for arterial-venous EC specification and the development of lymphatic and vascular structures (43-46). During development, the expression of Sox2 is sustained along the ectoderm (42), where organs emerge from interactions between the epithelium and the mesenchyme (47). Sox2 has also been shown to be essential for differentiation of multiple lineages (29, 47-50), somatic cell reprogramming (42), and cell fate transitions $(51,52)$. In this study, we identified excess Sox 2 signaling in cerebral AVMs, which disrupted the transcriptional landscape of EC differentiation and led to emerging mesenchymal characteristics in the cerebral ECs. We also observed that the induction of Sox 2 was accompanied by an induction of the stem cell markers Klf4 and c-Myc, but not of Oct3/4. Oct3/4, Sox2, Klf4, and c-Myc, referred to as the Yamanaka factors, are used to induce pluripotency in somatic cells (53). It is possible that, without the induction of Oct3/4, the Sox2-induced EndMTs may be limited in regard to differentiation potential. We argue that better understanding of cell differentiation subsequent to EndMTs would be helpful for counteracting pathological processes caused by EndMTs.

Sox2 may participate in crosstalk with other signaling pathways in AVMs, such as the RAS/MAPK pathway. Gene mutations in the RAS/MAPK pathway, such as KRAS, NRAS, BRAF, and MAP2K1, have been found to cause sporadic vascular malforma- 
tions (54). Mutations of MAP2K1 in somatic cells are also associated with extracranial AVMs (55), and mutations of RASA1 are associated with capillary AVMs (56). Interestingly, Sox2 has been identified in crosstalks with the MAPK pathway during regulation of mesenchymal characteristics in tumor cells (57), and activation of the MAPK pathway regulates the proliferation and differentiation of Sox2-positive cells (58). Levels of Sox2 strongly affect tumorigenesis induced by KRAS activation (59), and elevated Sox2 inhibits osteoblastic differentiation through the MAPK pathway (60). Thus, it would be of interest to explore the interaction between Sox2 and the RAS/MAPK pathways in cerebral AVMs.

We found that Sox2 directly regulates JMJD5 expression and activates the expression of mesenchymal markers in ECs. JMJD5 has been previously identified as a histone demethylase in the regulation of cancer cell proliferation (61), embryonic development (62), and pluripotency in embryonic stem cells (63). We showed that JMJD5 is induced by excess Sox 2 and provided JMJD5 as a Sox2 downstream target that worked together with Sox2 in the transcriptional regulation of cell differentiation.

Our results showed that genetic suppression of Sox2 in the endothelium improved cerebral AVMs. For potential clinical translation, we identified the chemical compound pronethalol as an inhibitor of Sox2 expression using a high-throughput technique and showed that it improves cerebral AVMs in $M g p^{-/-}$mice. Pronethalol is an antagonist of $\beta$-adrenergic receptors (64) and has been reported to successfully treat cardiovascular disease in animal models (64). However, neurological side effects in clinical trials and moderately potent carcinogenesis in mice are limiting factors in long-term treatment with pronethalol (64). It is possible that the side effects of pronethalol may be related to Sox 2 expression, since Sox 2 is an important factor in the development of the neurological system (29) and carcinogenesis (52). Compared with the dose in previous studies, we used a much lower dose of pronethalol, which may reduce the risk of potential side effects. Furthermore, it is possible that other $\beta$-adrenergic receptor blockers are as efficient as pronethalol in regard to Sox 2 expression, but without the side effects. For example, propranolol has a $\beta$-blocking activity similar to that of pronethalol, but without the tumorigenic effects (64). Indeed, a number of $\beta$-adrenergic receptor blockers inhibit the expression of Sox 2 (Figure 8) and might exert part of their clinical effects through Sox 2 inhibition. Thus, the effects of $\beta$-adrenergic antagonists on cerebral AVMs need further investigation.

Altogether, we find that excess Sox 2 signaling alters the transcriptional landscape of brain ECs and causes lumen disorder in cerebral AVMs. Suppression of Sox 2 expression normalizes EC differentiation and lumen formation, thereby improving cerebral AVMs.

\section{Methods}

Animals. $\mathrm{Mgp}^{+/-}$(B6.129S7-Mgptm1Kry/KbosJ), Cdh5 $5^{\text {Cre }}$ (B6.Cg-Tg (Cdh5-cre)7Mlia/J), and Sox $2^{f / f l}$ (Sox2tm1.1Lan/J) mice on a C57BL/6J background were purchased from the Jackson Laboratory. Genotypes were confirmed by PCR (65), and experiments were performed with generation F4-F6. Littermates were used as WT controls. All mice were fed a standard chow diet (catalog 8604, HarlanTeklad Laboratory).

Lesions of human cerebral AVMs. Deidentified specimens were obtained from the Department of Pathology, David Geffen School of Medicine at UCLA.
Tissue culture. HBMECs were purchased from ScienCell Research Laboratories and cultured per the manufacturer's protocol. For MGP depletion using CRISPR/Cas9 genomic editing, HBMECs were infected by lentiviral vectors that contained gRNA for exon 1 of the $M g p$ gene and Cas9 (Sigma-Aldrich). The infected cells were selected by puromycin. The positive clones were collected and expanded after 14 days of selection. The depletion of MGP was confirmed by real-time PCR. Transient transfections of HBMECs with siRNA (Silencer Predesigned siRNA, Applied Biosystems) were optimized and performed as previously described (24). When compared with unrelated control siRNA and scrambled siRNA, the selected siRNAs resulted in a $90 \%-$ 95\% decrease in mRNA and protein levels, as determined by real-time PCR and immunoblotting, respectively. Silencer Pre-designed siRNAs were obtained for Sox2 and JMJD5.

$\mu C T$ imaging. $\mu \mathrm{CT}$ was performed by Scanco USA Inc. Perfusion with the MICROFIL compound and preparation of the specimens were performed as previously described in detail (24). All the samples were scanned on a high-resolution, volumetric $\mu \mathrm{CT}$ scanner ( $\mu \mathrm{CT} 40$, Scanco Medical). The image data were acquired with the following parameters: $10 \mu \mathrm{m}$ isotropic voxel resolution; $200 \mathrm{~ms}$ exposure time; 2,000 views; and 5 frames per view. The $\mu$ CT-generated DICOM files were used to analyze the samples and to create volume renderings of the regions of interest. The raw data files were viewed using the MicroView 3-D volume viewer and analysis tool (GE Healthcare) and AltaViewer software. Additionally, images of the sample were generated using SCIRun (Scientific Computing and Imaging Institute).

Vascular shunting. Fluorescent microspheres of $15 \mu \mathrm{m}$ (Invitrogen) were injected into the left ventricle immediately after sacrificing the mice, and the tissues were examined and photographed under UV light.

RNA analysis. Real-time PCR analysis was performed as previously described (66). GAPDH was used as a control gene (66). Primers and probes for mouse Sox2, N-cadherin, Rasip1, Par3, $\beta 1$-integrin, c-kit, and JMJD5 were obtained from Applied Biosystems using TaqMan Gene Expression Assays.

Immunofluorescence. Immunofluorescence was performed as previously described in detail (17). We used specific antibodies for Sox2 (R\&D Systems, catalog MAB2018), N-cadherin (Thermo Fisher Scientific, catalog 33-3900), CD31 (Abcam, catalog ab32457) and JMJD5 (Abcam, catalog ab106391). Nuclei were stained with DAPI (Sigma-Aldrich).

Flow cytometric analysis. FACS analysis was performed as previously described (17). Cells were stained with FITC-, phycoerythrin(PE-), or Alexa Fluor 488-conjugated antibodies against Sox2 (R\&D Systems catalog MAB2018) and N-cadherin (Thermo Fisher Scientific, catalog 33-3900). Nonspecific fluorochrome- and isotype-matched IgGs (BD Biosciences - Pharmingen) served as controls.

Immunoblotting. Immunoblotting was performed as previously described (17). Equal amounts of tissue lysates were used for immunoblotting. Blots were incubated with specific antibodies to Sox2 (R\&D Systems, catalog MAB2018), JMJD5 (Abcam, catalog ab106391), N-cadherin (Thermo Fisher Scientific, catalog 33-3900), Par3 (Thermo Fisher Scientific, catalog PA5-45056), and Rasip1 (Invitrogen, catalog PA5-75798). $\beta$-Actin (1:5000 dilutions; Sigma-Aldrich, catalog A2228) was used as a loading control.

ChIP-Seq and ChIP assay. Specific antibodies were used to perform ChIP in order to enrich the genomic DNA from $\mathrm{Mgp}^{-/-}$and $M g \mathrm{p}^{+/+}$ cerebral ECs as described before (67). ChIP DNA were sequenced by the Technology Center for Genomics \& Bioinformatics at UCLA. 
Reads from each sample were mapped to the mouse genome by using Bowtie2. The homer tool was used to detect significant enrichment of peaks, with 5\% FDR and more than 4 folds over input. Motif occurrences in peaks were identified by the homer motif discovery function. Peak annotation was performed to associate peaks with nearby genes and calculate tag densities. Gene ontology analysis and pathway enrichment of identified genes were also performed (17). We used specific antibodies for Sox2 (R\&D Systems, catalog MAB2018), H3K27me3 (Abcam, catalog ab6002), and H3K4me3 (Abcam, catalog ab8580). All original microarray data were deposited in the NCBI's Gene Expression Omnibus database (GEO GSE129644).

The ChIP assay was performed as previously described (67). The specific antibodies for Sox2 (R\&D System, catalog MAB2018) and JMJD5 (Abcam, catalog ab106391) were used to enriched genomic DNA.

High-throughput system for the compound screen. ReNcell VM cells (Millipore, SCC008) were stably infected with Sox2 promoterdriven GFP by using Sox2-GFP lentivirus (GeneCopoeia). Plates were coated with laminin $(20 \mu \mathrm{g} / \mathrm{ml})$ and washed with PBS twice using an ELx 405 plate washer (BioTek Instruments). Cells in $25 \mu \mathrm{l}$ medium per well were loaded by Multidrop 384 (Thermo LabSystems). Then, chemical compounds were pinned to plates with media. GFP-positive ReNcell VM cells (positive control) and WT ReNcell VM cells (negative control) were also seeded. Plates were transferred to a Liconic STX $220 \mathrm{CO}_{2}$ plate incubator, and incubated for at least 3 days. Plates were transferred and delivered by a Thermo Spinnaker robotic arm on a rail. GFP expression was determined and imaged using a Flex Station II and Victor 3V.

Statistics. Analyses were performed using GraphPad InStat, version 3.0 (GraphPad Software). Data were analyzed by either unpaired 2-tailed Student's $t$ test or 1-way ANOVA with Tukey's multiple comparisons test for statistical significance. Data are represented as mean \pm SD. $P$ values of less than 0.05 were considered significant, and experiments were repeated a minimum of 3 times.

Study approval. Studies were approved by the Institutional Review Board and conducted in accordance with the animal care guidelines set by the University of California, Los Angeles. The investigation conformed to guidelines in the Guide for the Care and Use of Laboratory Animals (National Academies Press, 2011). Human specimens were not obtained specifically for this research, and none of the investigators involved in the research are able to ascertain the identity of the subjects. Human subject research exemptions were approved by the Office of Human Research Protection Program at UCLA.

\section{Author contributions}

YY supervised the experiments, analyzed data, and wrote the manuscript. JY, XW, DZ, LW, LZ, EXR, CH, and KIB performed experiments and data analysis.

\section{Acknowledgments}

Funding for this work was provided in part by NIH grants NS79353 (to YY), HL139675 (to YY), HL30568 (to KIB), and HL81397 (to KIB). We thank Robert Damoiseaux at UCLA for the chemical compound screen.

Address correspondence to: Yucheng Yao, Division of Cardiology, David Geffen School of Medicine at UCLA, Box 951679, Los Angeles, California 90095-1679. Phone: 310.825.3239; Email: yyao@ mednet.ucla.edu.
1. Friedlander RM. Clinical practice. Arteriovenous malformations of the brain. N Engl JMed. 2007;356(26):2704-2712.

2. Yao Y, et al. Reducing Jagged 1 and 2 levels prevents cerebral arteriovenous malformations in matrix Gla protein deficiency. Proc Natl Acad Sci US A. 2013;110(47):19071-19076.

3. Murphy PA, et al. Endothelial Notch4 signaling induces hallmarks of brain arteriovenous malformations in mice. Proc Natl Acad Sci U S A. 2008;105(31):10901-10906.

4. Carlson TR, et al. Endothelial expression of constitutively active Notch4 elicits reversible arteriovenous malformations in adult mice. Proc Natl Acad Sci U S A. 2005;102(28):9884-9889.

5. Murphy PA, Kim TN, Lu G, Bollen AW, Schaffer $\mathrm{CB}$, Wang RA. Notch4 normalization reduces blood vessel size in arteriovenous malformations. Sci Transl Med. 2012;4(117):117ra8.

6. Jabbour MN, et al. Aberrant angiogenic characteristics of human brain arteriovenous malformation endothelial cells. Neurosurgery. 2009;64(1):139-146.

7. Weinstein N, Mendoza L, Gitler I, Klapp J. A network model to explore the effect of the microenvironment on endothelial cell behavior during angiogenesis. Front Physiol. 2017;8:960.

8. Li DY, et al. Defective angiogenesis in mice lacking endoglin. Science. 1999;284(5419):1534-1537.

9. Urness LD, Sorensen LK, Li DY. Arteriovenous malformations in mice lacking activin recep- tor-like kinase-1. Nat Genet. 2000;26(3):328-331.

10. Prigoda NL, et al. Hereditary haemorrhagic telangiectasia: mutation detection, test sensitivity and novel mutations. JMed Genet. 2006;43(9):722-728.

11. Abdalla SA, Letarte M. Hereditary haemorrhagic telangiectasia: current views on genetics and mechanisms of disease. JMed Genet. 2006;43(2):97-110.

12. Shovlin CL. Hereditary haemorrhagic telangiectasia: pathophysiology, diagnosis and treatment. Blood Rev. 2010;24(6):203-219.

13. Uyttendaele H, Ho J, Rossant J, Kitajewski J. Vascular patterning defects associated with expression of activated Notch 4 in embryonic endothelium. Proc Natl Acad Sci U S A. 2001;98(10):5643-5648.

14. Maddaluno L, et al. EndMT contributes to the onset and progression of cerebral cavernous malformations. Nature. 2013;498(7455):492-496.

15. Yao J, et al. Matrix Gla protein regulates differentiation of endothelial cells derived from mouse embryonic stem cells. Angiogenesis. 2016;19(1):1-7.

16. McDonald JE, Miller FJ, Hallam SE, Nelson L, Marchuk DA, Ward KJ. Clinical manifestations in a large hereditary hemorrhagic telangiectasia (HHT) type 2 kindred. Am JMed Genet. 2000;93(4):320-327.

17. Yao Y, Jumabay M, Ly A, Radparvar M, Cubberly $\mathrm{MR}$, Boström KI. A role for the endothelium in vascular calcification. Circ Res. 2013;113(5):495-504.
18. Medici D, Shore EM, Lounev VY, Kaplan FS, Kalluri R, Olsen BR. Conversion of vascular endothelial cells into multipotent stem-like cells. Nat Med. 2010;16(12):1400-1406.

19. Xu K, et al. Blood vessel tubulogenesis requires Rasip1 regulation of GTPase signaling. Dev Cell. 2011;20(4):526-539.

20. Akhtar N, Streuli CH. An integrin-ILK-microtubule network orients cell polarity and lumen formation in glandular epithelium. Nat Cell Biol. 2013;15(1):17-27.

21. Zovein AC, et al. Beta1 integrin establishes endothelial cell polarity and arteriolar lumen formation via a Par3-dependent mechanism. Dev Cell. 2010;18(1):39-51.

22. Yao J, et al. Serine protease activation essential for endothelial-mesenchymal transition in vascular calcification. Circ Res. 2015;117(9):758-769.

23. Rios Garcia M, et al. Acetyl-CoA carboxylase 1-dependent protein acetylation controls breast cancer metastasis and recurrence. Cell Metab. 2017;26(6):842-855.e5.

24. Yao Y, Jumabay M, Wang A, Boström KI. Matrix Gla protein deficiency causes arteriovenous malformations in mice. JClin Invest. 2011;121(8):2993-3004.

25. Goligorsky MS. Microvascular rarefaction: the decline and fall of blood vessels. Organogenesis. 2010;6(1):1-10.

26. Yao Y, Shahbazian A, Boström KI. Proline and gamma-carboxylated glutamate residues 
in matrix Gla protein are critical for binding of bone morphogenetic protein-4. Circ Res. 2008;102(9):1065-1074.

27. Campolo F, et al. Essential role of Sox 2 for the establishment and maintenance of the germ cell line. Stem Cells. 2013;31(7):1408-1421.

28. Ragge NK, et al. SOX2 anophthalmia syndrome. Am JMed Genet A. 2005;135(1):1-7.

29. Amador-Arjona A, et al. SOX2 primes the epigenetic landscape in neural precursors enabling proper gene activation during hippocampal neurogenesis. Proc Natl Acad Sci U S A. 2015;112(15):E1936-E1945.

30. Wernig $\mathrm{M}$, et al. In vitro reprogramming of fibroblasts into a pluripotent ES-cell-like state. Nature. 2007;448(7151):318-324.

31. $\mathrm{Yu}$ J, et al. Induced pluripotent stem cell lines derived from human somatic cells. Science. 2007;318(5858):1917-1920.

32. Takahashi K, et al. Induction of pluripotent stem cells from adult human fibroblasts by defined factors. Cell. 2007;131(5):861-872.

33. Choi SH, et al. A three-dimensional human neural cell culture model of Alzheimer's disease. Nature. 2014;515(7526):274-278.

34. Evrard SM, et al. Endothelial to mesenchymal transition is common in atherosclerotic lesions and is associated with plaque instability. Nat Commun. 2016;7:11853.

35. Boström KI, Yao J, Guihard PJ, Blazquez-Medela AM, Yao Y. Endothelial-mesenchymal transition in atherosclerotic lesion calcification. Atherosclerosis. 2016;253:124-127.

36. Guihard PJ, Yao J, Blazquez-Medela AM, Iruela-Arispe L, Boström KI, Yao Y. Endothelial-mesenchymal transition in vascular calcification of Ins2Akita/+ mice. PLOS ONE. 2016;11(12):e0167936.

37. Axnick J, Lammert E. Vascular lumen formation. Curr Opin Hematol. 2012;19(3):192-198.

38. Xu K, Chong DC, Rankin SA, Zorn AM, Cleaver O. Rasip1 is required for endothelial cell motility, angiogenesis and vessel formation. Dev Biol. 2009;329(2):269-279.

39. Yao Y, Nowak S, Yochelis A, Garfinkel A, Boström KI. Matrix GLA protein, an inhibitory morphogen in pulmonary vascular development. J Biol Chem. 2007;282(41):30131-30142.

40. Murphy PA, et al. Constitutively active Notch4 receptor elicits brain arteriovenous malformations through enlargement of cap- illary-like vessels. Proc Natl Acad Sci U S A. 2014;111(50):18007-18012.

41. Wegner M. From head to toes: the multiple facets of Sox proteins. Nucleic Acids Res. 1999;27(6):1409-1420.

42. Sarkar A, Hochedlinger K. The sox family of transcription factors: versatile regulators of stem and progenitor cell fate. Cell Stem Cell. 2013;12(1):15-30.

43. Park C, Kim TM, Malik AB. Transcriptional regulation of endothelial cell and vascular development. Circ Res. 2013;112(10):1380-1400.

44. Herpers R, van de Kamp E, Duckers HJ, Schulte-Merker S. Redundant roles for sox 7 and sox 18 in arteriovenous specification in zebrafish. Circ Res. 2008;102(1):12-15.

45. Pendeville H, et al. Zebrafish Sox7 and Sox18 function together to control arterial-venous identity. Dev Biol. 2008;317(2):405-416.

46. Sakamoto Y, et al. Redundant roles of Sox17 and Sox18 in early cardiovascular development of mouse embryos. Biochem Biophys Res Commun. 2007;360(3):539-544.

47. Pispa J, Thesleff I. Mechanisms of ectodermal organogenesis. Dev Biol. 2003;262(2):195-205.

48. Ochieng JK, et al. Sox 2 regulates the emergence of lung basal cells by directly activating the transcription of Trp63. Am J Respir Cell Mol Biol. 2014;51(2):311-322.

49. Clavel C, et al. Sox 2 in the dermal papilla niche controls hair growth by fine-tuning BMP signaling in differentiating hair shaft progenitors. Dev Cell. 2012;23(5):981-994.

50. Basu-Roy U, Ambrosetti D, Favaro R, Nicolis SK, Mansukhani A, Basilico C. The transcription factor Sox2 is required for osteoblast self-renewal. Cell Death Differ. 2010;17(8):1345-1353.

51. Mandalos N, et al. Sox 2 acts as a rheostat of epithelial to mesenchymal transition during neural crest development. Front Physiol. 2014;5:345.

52. Luo W, Li S, Peng B, Ye Y, Deng X, Yao K. Embryonic stem cells markers SOX2, OCT4 and Nanog expression and their correlations with epithelialmesenchymal transition in nasopharyngeal carcinoma. PLOS ONE. 2013;8(2):e56324.

53. Takahashi K, Yamanaka S. Induction of pluripotent stem cells from mouse embryonic and adult fibroblast cultures by defined factors. Cell. 2006;126(4):663-676.

54. Al-Olabi L, et al. Mosaic RAS/MAPK variants cause sporadic vascular malformations which respond to targeted therapy. JClin Invest.
2018;128(11):5185 .

55. Couto JA, et al. Somatic MAP2K1 mutations are associated with extracranial arteriovenous malformation. Am JHum Genet. 2017;100(3):546-554.

56. Revencu N, et al. RASA1 mutations and associated phenotypes in 68 families with capillary malformation-arteriovenous malformation. Hum Mutat. 2013;34(12):1632-1641.

57. Hui K, et al. RASAL2, a RAS GTPase-activating protein, inhibits stemness and epithelial-mesenchymal transition via MAPK/SOX2 pathway in bladder cancer. Cell Death Dis. 2017;8(2):e2600.

58. Haston S, et al. MAPK pathway control of stem cell proliferation and differentiation in the embryonic pituitary provides insights into the pathogenesis of papillary craniopharyngioma. Development. 2017;144(12):2141-2152.

59. Xu X, et al. The cell of origin and subtype of K-Ras-induced lung tumors are modified by Notch and Sox2. Genes Dev. 2014;28(17):1929-1939.

60. Ding D, Xu H, Liang Q, Xu L, Zhao Y, Wang Y. Over-expression of Sox 2 in C3H10T1/2 cells inhibits osteoblast differentiation through Wnt and MAPK signalling pathways. Int Orthop. 2012;36(5):1087-1094.

61. Hsia DA, et al. KDM8, a H3K36me2 histone demethylase that acts in the cyclin A1 coding region to regulate cancer cell proliferation. Proc Natl Acad Sci U S A. 2010;107(21):9671-9676.

62. Ishimura A, Minehata K, Terashima M, Kondoh G, Hara T, Suzuki T. Jmjd5, an H3K36me2 histone demethylase, modulates embryonic cell proliferation through the regulation of Cdkn1a expression. Development. 2012;139(4):749-759.

63. Zhu H, Hu S, Baker J. JMJD5 regulates cell cycle and pluripotency in human embryonic stem cells. Stem Cells. 2014;32(8):2098-2110.

64. Black JW, Duncan WA, Shanks RG. Comparison of some properties of pronethalol and propranolol. Br JPharmacol Chemother. 1965;25(3):577-591.

65. Yao Y, et al. Crossveinless 2 regulates bone morphogenetic protein 9 in human and mouse vascular endothelium. Blood. 2012;119(21):5037-5047.

66. Boström K, Zebboudj AF, Yao Y, Lin TS, Torres A. Matrix GLA protein stimulates VEGF expression through increased transforming growth factorbeta1 activity in endothelial cells. J Biol Chem. 2004;279(51):52904-52913.

67. Yao J, et al. Vascular endothelium plays a key role in directing pulmonary epithelial cell differentiation. J Cell Biol. 2017;216(10):3369-3385. 